This is a post-peer-review, pre-copyedit version of an article published in Pharmaceutical Research. The final authenticated version is available online at: https://doi.org/10.1007/ s11095-012-0683-y 


\section{Click Chemistry with Polymers, Dendrimers, and Hydrogels for Drug Delivery}

Enrique Lallana, ${ }^{1}$ Francisco Fernandez-Trillo, ${ }^{1}$ Ana Sousa-Herves, ${ }^{1}$ Ricardo Riguera, ${ }^{1}$ and Eduardo Fernandez-Megia ${ }^{1,2}$

${ }^{1}$ Department of Organic Chemistry and Center for Research in Biological Chemistry and

Molecular Materials (CIQUS), University of Santiago de Compostela, Jenaro de la Fuente s/n, 15782 Santiago de Compostela, Spain

${ }^{2}$ To whom correspondence should be addressed

E-mail:ef.megia@usc.es

Running Title: Clicking Polymers for Drug Delivery 


\section{Abbreviations}

AIBN (azobisisobutyronitrile), ATRP (atom transfer radical polymerization), BPDS (bathophenanthroline disulphonated disodium salt), CA (contrast agent), CL (caprolactone), ConA (Concanavalin A), CPT (camptothecin), CuAAC [Cu(I)-catalyzed azide-alkyne cycloaddition], DBU (1,8-diazabicyclo[5.4.0]undec-7-ene), DDS (drug delivery system), DIPEA (N,N-diisopropylethylamine), DMPA (2,2-dimethoxy-2-phenylacetophenone), DOX (doxorubicin), EPR (enhanced permeability and retention), GATG (gallic acid-triethylene glycol), LCST (lower critical solution temperature), LRP (living radical polymerization), NMP ( $N$-methyl-2-pyrrolidone), MAPC (methacryloyloxyethyl phosphorylcholine), MMP (matrix metalloproteinase), bis-MPA [2,2-bis(hydroxymethyl)propionic acid], MRI (magnetic resonance imaging), MSC (mesenchymal stem cells), PAMAM [poly(amido amine)], PEI [poly(ethylene imine)], PEO [poly(ethylene oxide)], PEG [poly(ethylene glycol)], PIC (polyion complex), PLL (poly-L-lysine), PMA (propargyl methacrylate), PMDETA $\left(N, N, N^{\prime}, N^{\prime}, N^{\prime \prime}-\right.$ pentamethyldiethylenetriamine), PMMA [poly(methyl methacrylate)], PNIPAM $[\operatorname{poly}(N-$ isopropylacrylamide)], POEGA [poly(oligo(ethylene glycol) acrylate)], PPI [poly(propylene imine)], PS [poly(styrene)], PVA [poly(vinyl alcohol)], RAFT (reversible addition-fragmentation chain transfer), RGD (Arg-Gly-Asp), ROMP (ring-opening methathesis polymerization), ROS (reactive oxygen species), SPAAC (strain-promoted azide-alkyne cycloaddition), SPR (surface plasmon resonance), TBTA [tris(benzyltriazolylmethyl)amine], TEC (thiol-ene coupling), THPTA [tris(hydroxypropyltriazolylmethyl)amine], TMS (trimethylsilyl), TYC (thiol-yne coupling).

\section{Clicking Polymers for Drug Delivery}




\begin{abstract}
During the last decades, great efforts have been devoted to design polymers for reducing the toxicity, increasing the absorption, and improving the release profile of drugs. Advantage has been also taken from the inherent multivalency of polymers and dendrimers for the incorporation of diverse functional molecules of interest in targeting and diagnosis. In addition, polymeric hydrogels with the ability to encapsulate drugs and cells have been developed for drug delivery and tissue engineering applications. In the long road to this successful story, pharmaceutical sciences have been accompanied by parallel advances in synthetic methodologies allowing the preparation of precise polymeric materials with enhanced properties. In this context, the introduction of the click concept by Sharpless and coworkers in 2001 focusing the attention on modularity and orthogonality has greatly benefited polymer synthesis, an area where reaction efficiency and product purity are significantly challenged. The purpose of this Expert Review is to discuss the impact of click chemistry in the preparation and functionalization of polymers, dendrimers, and hydrogels of interest in drug delivery.
\end{abstract}

Keywords: click chemistry; drug delivery; polymer; dendrimer; hydrogel 
"The reaction must be modular, wide in scope, give very high yields, generate only inoffensive byproducts that can be removed by nonchromatographic methods, and be stereospecific (but not necessarily enantioselective). The required process characteristics include simple reaction conditions (ideally, the process should be insensitive to oxygen and water), readily available starting materials and reagents, the use of no solvent or a solvent that is benign (such as water) or easily removed, and simple product isolation. Purification - if required - must be by nonchromatographic methods, such as crystallization or distillation, and the product must be stable under physiological conditions... Click processes proceed rapidly to completion and also tend to be highly selective for a single product: we think of these reactions as being "spring-loaded" for a single trajectory". H. C. Kolb, M. G. Finn and K. B. Sharpless. Angew. Chem., Int. Ed. 40: 2004-2021 (2001).

\section{INTRODUCTION}

Since the mid-1960s, great efforts have been devoted to the development of drug delivery systems (DDS) for the controlled administration of drugs (1). Encouraged by breakthroughs in the field [PEGylation, active targeting, enhanced permeability and retention (EPR) effect] and the need of more sophisticated materials and novel designs, chemists have perceived drug delivery as an attractive field to collaborate with colleagues in the pharmaceutical and medical sciences. Indeed, the ability of putting together small building blocks into larger structures has been at the core of evolution and inspired chemists in the search of more efficient processes with production of minimal waste (2). In this context, Sharpless and coworkers introduced in 2001 the concept of click chemistry in an effort to focus the attention on the easy production of properties

\section{Clicking Polymers for Drug Delivery}


rather than on challenging structures (3). The idea behind click chemistry is to deliver new avenues for the preparation of useful materials from readily available building blocks and extremely efficient chemical transformations. During the last decade the click philosophy has received a warm welcome by researchers in different fields and inspired the publication of hundreds of papers in areas such as, materials and polymer science, nanotechnology, and drug delivery and the pharmaceutical sciences in general (4, 5, 6, 7). In a previous Expert Review, we have critically discussed the click concept, its advantages, uses and misuses, as well as its application for the preparation and functionalization of nanosized DDS (8). As the vast majority of these examples rely on the $\mathrm{Cu}(\mathrm{I})$-catalyzed azide-alkyne cycloaddition (CuAAC) $(9,10)$, a section dealing with the use of this reaction in bioconjugation was provided, covering the role of $\mathrm{Cu}$ in the structural damage of biomolecules, the use of $\mathrm{Cu}(\mathrm{I})$-chelating ligands (Fig. 1), and the development of the $\mathrm{Cu}$-free strain-promoted azide-alkyne cycloaddition (SPAAC) (11). More recently, a detailed perspective on the efficient application of CuAAC and SPAAC for the in vitro functionalization of biomacromolecules has been published by our group (12).

Fig. 1

During the last decades, a great deal of work has been devoted to adapt, modify, or tailor polymers for reducing drug toxicity, increasing drug absorption, and improving drug release profiles (13). These efforts have indeed benefited from the emergence of the click concept. Thus, although the main application of click chemistry originally envisaged by Sharpless and coworkers was oriented to drug discovery, the click concept has profoundly impacted polymer

\section{Clicking Polymers for Drug Delivery}


synthesis, an area where reaction efficiency and product purity are significantly challenged (14). In this Expert Review a survey of the most recent applications of CuAAC and other click reactions, including Michael addition, Diels-Alder, thiol-ene coupling (TEC), and SPAAC for the preparation and functionalization of dendrimers, synthetic polymers, and hydrogels will be discussed with special emphasis on those examples of relevance in drug delivery. The review has been divided into the following sections:

\section{DENDRIMERS}

Synthesis of Dendrimers

Periphery Functionalization

CuAAC Functionalization with Carbohydrates

CuAAC Functionalization with Peptides

CuAAC Functionalization with Nucleotides

CuAAC Functionalization with non-Naturally Occurring Molecules

Periphery Functionalization by Click Chemistries other than CuAAC

\section{SYNTHETIC POLYMERS}

Polymer Synthesis: Linear Polymers

Side Chain Functionalization of Polymers and Synthesis of Graft Copolymers

End Group Functionalization of Polymers and Synthesis of Block Copolymers

Preparation and Functionalization of Cyclic Polymers

\section{HYDROGELS}

Michel Addition in the Preparation of Hydrogels

Diels-Alder Cycloaddition in the Preparation of Hydrogels

\section{Clicking Polymers for Drug Delivery}


Lallana Page 7

CuAAC and SPAAC in the Preparation of Hydrogels 


\section{DENDRIMERS}

Dendrimers are perfectly monodisperse macromolecules made of branched repeating units emerging from a central core, that are characterized by a high degree of functionality (15). In general, they have globular shape with diameters in the nanometer scale $(c a .1-20 \mathrm{~nm})$, which makes them ideal candidates for bio- and nanotechnology applications (16). The branched architecture of dendrimers demands rigorous synthetic protocols for their preparation, which normally involve activation/growing steps and tedious purifications. In this context, it is not surprising that the preparations of some of the most successful dendritic scaffolds have relied on click reactions appeared before the click concept being proposed. This is for example the case of poly(amido amine) (PAMAM) (17) and poly(propylene imine) (PPI) (18) dendrimers, which rely on Michael additions in their growing steps, or glycerol dendrimers which use a dihydroxylation reaction as activation step (19). In this section we will focus the attention on reports that adopting the original paper by Sharpless (3) as source of inspiration have made significant contributions to the preparation and functionalization of dendrimers for drug delivery applications.

\section{Synthesis of Dendrimers}

The first application of $\mathrm{CuAAC}$ to the synthesis of dendrimers was reported in 2004 as a result of collaboration between the groups of Hawker, Voit, Fréchet, Sharpless, and Fokin (20). A convergent $\mathrm{CuAAC}$-based approach was employed for the preparation of triazol dendrimers mimicking the earlier synthesis by Fréchet and Hawker developed in 1990 (21). CuAAC $\left(\mathrm{CuSO}_{4}\right.$, ascorbate, $\left.t-\mathrm{BuOH}-\mathrm{H}_{2} \mathrm{O}\right)$ revealed to be a much more efficient methodology than the

\section{Clicking Polymers for Drug Delivery}


originally reported nucleophilic substitution. Thus, not only stoichiometric amounts of azide and alkyne partners were employed, but also chromatographic purifications were avoided in most of the cases. Shortly after, a complementary CuAAC-based divergent synthesis of dendrimers was reported by the groups of Hawker and Wooley (22).

Mutifunctionalized dendrimers represent one of the most interesting dendritic architectures for drug delivery. They offer the possibility of selectively localizing diverse functional molecules (e.g., drugs, targeting ligands, imaging agents) while exploiting their inherent multivalency. In this regard, a collaboration between the groups of Finn, Fokin, Sharpless, and Hawker demonstrated the usefulness of CuAAC for the preparation of Janus-type dendrimers, where protected and unprotected 2,2-bis(hydroxymethyl)propionic acid (bis-MPA) dendrons were connected through their focal points via triazole linkages $\left[\mathrm{Cu}\left(\mathrm{PPh}_{3}\right)_{3} \mathrm{Br}\right.$, DIPEA, THF, $\left.50{ }^{\circ} \mathrm{C}\right]$ (Fig. 2a) (23). In addition, an adequate selection of protecting groups allowed the stepwise $\mathrm{CuAAC}$ functionalization of the resulting dendrimers $\left(\mathrm{CuSO}_{4}\right.$, ascorbate, THF- $\left.\mathrm{H}_{2} \mathrm{O}\right)$ with 16 mannose units on one side of the dendrimer, and 2 coumarin dyes on the other. The resulting glycodendrimer showed a 240 -fold increase affinity towards lectin Concanavalin A (ConA) in hemagglutination experiments compared to monomeric mannose which entails a rich future for these structures in antiadhesive therapy. In a similar fashion, the group of Sanyal has reported the preparation of bifunctional Janus-type dendrimers based on a Diels-Alder cycloaddition (benzene, $85^{\circ} \mathrm{C}$ ) between furan-functionalized Fréchet dendrons and maleimide-functionalized bis-MPA dendrons (Fig. 2b) (24).

Another interesting approach for the selective localization of various functionalities in dendrimers relies on the use of repeating units of the type $\mathrm{AB}_{2} \mathrm{C}$ carrying three orthogonal

\section{Clicking Polymers for Drug Delivery}


handles. As described by Malkoch and coworkers, this strategy has allowed the preparation of bifunctional dendrimers of generation 1-3 (G1-G3) bearing up to 24 hydroxyl groups at the periphery and 21 internal alkyne/azide groups distributed throughout the dendrimer backbone, which were amenable for further functionalization by means of CuAAC (Fig. 2c) (25).

Fig. 2

Since the synthesis of dendrimers demands a high degree of control over activation and growing steps, chemists have found in this process an excellent test bank for the assessment of emerging click technologies. This has been the case for example for the thiol-ene coupling (TEC), firstly exploited by Hawker and coworkers in the dendrimer arena starting from a trisalkene triazine core and 1-thioglycerol (26). Reactions were carried out in bulk (UV light, 365 $\mathrm{nm})$ without the need of removal of oxygen, and required only 1.5 equiv of thiol partner. The absence of byproducts allowed easy purifications by precipitation up to G4. In a similar fashion, the group of Stenzel has reported the preparation of related thio-ether dendrimers by means of thiol-yne coupling (TYC) (UV light, $365 \mathrm{~nm}$, DMF) (27). Interestingly, as alkynes allow the addition of two thiols, dendrimers with a higher degree of functionalization could be readily prepared through this approach. This way, three generations of thio-ether dendrimers peripherally decorated with carboxylic acids were prepared and their potential in drug delivery illustrated by complexation to cis-dichlorodiamineplatinum(II).

Hawker, Albertazzi, and coworkers have more recently reported a combination of nucleophilic ring-opening of epoxides by amines and TEC (UV light, $365 \mathrm{~nm}, \mathrm{MeOH}$ ) or TYC

\section{Clicking Polymers for Drug Delivery}


[DMPA (2,2-dimethoxy-2-phenylacetophenone), $\mathrm{MeOH}$, UV light; or AIBN, $\mathrm{MeOH}, 80^{\circ} \mathrm{C}$ ] as a useful methodology for the preparation of dendrimers and PEG-dendritic block copolymers internally functionalized with hydroxyl groups $(28,29)$. These examples are unique in the application of two different click reactions for both the activation and growing steps. The covalent attachment of hydrophobic drugs/imaging agents at these internal hydroxyl groups was envisaged as an effective way to provide conjugates with solubility and biocompatibility properties similar to those of the unconjugated dendritic scaffold.

As seen in Fig. 3, click chemistry has also revealed very useful for the accelerated preparation of dendrimers from repeating units carrying orthogonal functionalities. Such a strategy results in a significant reduction of synthetic effort since intermediate activation steps are avoided and hence, every step translates into a new dendrimer generation. A pioneering example in this field was reported back in 2001 by the group of Caminade and Majoral for the synthesis of phosphorous-dendrimers involving hydrazone linkages in one of the growing steps (Fig. 3) $(30,31)$. More recently, similar strategies have been implemented by the groups of Hawker and Malkoch for the preparation of benzyl ether and bis-MPA dendrimers combining $\mathrm{CuAAC}\left(\mathrm{CuSO}_{4}\right.$, ascorbate, THF- $\left.\mathrm{H}_{2} \mathrm{O}, 40^{\circ} \mathrm{C}\right)$ and etherification/esterification steps (Fig. 3) (32). It has not been until recently, however, that two different click reactions have been combined for this purpose by the group of Kakkar $\left[\mathrm{CuAAC}\left(\mathrm{CuSO}_{4}\right.\right.$, ascorbate, THF- $\mathrm{H}_{2} \mathrm{O}$, microwaves, $\left.65^{\circ} \mathrm{C}\right)$ and Diels-Alder (EtOAc, $50^{\circ} \mathrm{C}$ )] (Fig. 3) (33). This principle has been further pushed to the limit by the groups of Malkoch and Hawker by synthesizing a $6^{\text {th }}$ generation dendrimer in a single day by combination of TEC (UV light, $365 \mathrm{~nm}$, THF) and $\mathrm{CuAAC}\left(\mathrm{CuSO}_{4}\right.$, ascorbate, THF- $\left.\mathrm{H}_{2} \mathrm{O}\right)$ reactions (Fig. 3) (34).

\section{Clicking Polymers for Drug Delivery}


Fig. 3

\section{Periphery Functionalization}

As a consequence of their branched structure, dendrimers display a high number of functional groups at their periphery, which strongly determine their solubility and biological properties. The development of efficient strategies for their peripheral functionalization is therefore of great interest for advanced drug delivery applications. The group of Hawker showed in 2005 the usefulness of $\mathrm{CuAAC}$ for this purpose by the efficient functionalization of various alkynated dendritic scaffolds (benzyl ether, bis-MPA, PPI) with a small library of azides (35). As opposed to traditional functionalization procedures, only a slight excess of reactive azides was necessary under the reported conditions, being high dilution the only required precaution to avoid acetylene homocoupling.

\section{CuAAC Functionalization with Carbohydrates}

The high versatility of $\mathrm{CuAAC}$ has been exploited for the decoration of dendrimers with unprotected ligands of relevance in drug delivery. Carbohydrates regulate a myriad of biological and pathological processes in Nature. Recognition events such as fertilization, pathogen invasion, toxin and hormone mediation, and cell-cell interactions rely on multivalent carbohydrate-receptor interactions (36). This cluster glycoside effect has prompted the development of glycodendrimers and other synthetic multivalent glycoconjugates with the ability to interact with target lectins and hence, to promote/inhibit natural carbohydrate-receptor interactions (37). Pioneering examples on the preparation of glycodendrimers from unprotected

\section{Clicking Polymers for Drug Delivery}


carbohydrates came from the groups of Liskamp/Pieters (38), Finn/Fokin/Sharpless/Hawker (23) (Fig. 2a), and Fernandez-Megia/Riguera (Fig. 4) $(39,40)$. It is worth to note that, while the first two reports relied on alkynated dendrimers, the group of Fernandez-Megia and Riguera employed gallic acid-triethylene glycol (GATG) dendrimers incorporating terminal azide groups on their periphery. This way, glyco-dendrimers and PEG-dendritic block copolymers were efficiently prepared while ruling out the possibility of dendrimer dimerization. Typical reaction conditions involved a small excess of alkynated carbohydrates $\left(\mathrm{CuSO}_{4}\right.$, ascorbate, $\left.t-\mathrm{BuOH}-\mathrm{H}_{2} \mathrm{O}\right)$ and isolation of the resulting functionalized dendrimers by ultrafiltration. The study of the interaction of these glycodendrimers with lectins by means of surface plasmon resonance (SPR) shed valuable information on the interpretation of multivalent carbohydrate recognition, highlighting the importance of the density of lectin clusters on biological surfaces as a potential source of selectivity in drug delivery (Fig. 4) (41).

Fig. 4

\section{CuAAC Functionalization with Peptides}

Peptides are another interesting class of ligands that have been exploited for the functionalization of dendrimers. Peptide-dendrimer conjugates constitute valuable tools for the analysis of a variety of multivalent processes such as bacteria adhesion, cell proliferation, and allergic responses. For instance, Arg-Gly-Asp (RGD) tripeptide and cyclo(Arg-Gly-Asp-D-PheVal) $[\mathrm{c}(\mathrm{RGDfV})]$ pentapeptide are known to bind integrin $\alpha_{\mathrm{v}} \beta_{3}$, a membrane protein that plays an important role in tumor angiogenesis and metastasis (42). The group of Liskamp has investigated

\section{Clicking Polymers for Drug Delivery}


the CuAAC conjugation of RGD and $\mathrm{c}(\mathrm{RGDfV})$ peptides to dendrimers $\left(\mathrm{CuSO}_{4}\right.$, ascorbate, microwaves, THF- $\mathrm{H}_{2} \mathrm{O}, 100{ }^{\circ} \mathrm{C}$ ) and studied their increased affinity towards the $\alpha_{\mathrm{v}} \beta_{3}$ integrin receptor $(43,44)$. Functionalization with peptides proved to be more troublesome than with carbohydrates (38), as very low yields were obtained for the final conjugates in many cases. The same authors have also found that ${ }^{111}$ In-labeled RGD-dendrimers specifically exhibited an enhanced in vivo uptake into integrin $\alpha_{\mathrm{v}} \beta_{3}$ overexpressing tumors (44). Other biologically relevant peptides, such as antimicrobial magainin I and II, or Leu-enkephalin, have been successfully attached to the surface of dendrimers using similar CuAAC strategies (45).

\section{CuAAC Functionalization with Nucleotides}

Nucleotide ligands have been also installed on the surface of dendrimers. For instance, the group of Jacobson has recently decorated the surface of PAMAM dendrimers with nucleotide antagonists of the $\mathrm{P}_{2} \mathrm{Y}_{1}$ receptor by means of $\mathrm{CuAAC}\left(\mathrm{CuSO}_{4}\right.$, ascorbate, $\left.\mathrm{THF}-\mathrm{H}_{2} \mathrm{O}\right)$ in order to inhibit ADP-induced platelet aggregation (46). Interestingly, although no significant multivalent effect was observed, the affinity of these triazol-containing derivatives was higher than the corresponding amide-linked conjugates, indicating a positive effect of the triazole linker on activity. In a related work, the same research group has combined $\mathrm{CuAAC}\left(\mathrm{CuSO}_{4}\right.$, ascorbate, $t$ $\mathrm{BuOH}-\mathrm{H}_{2} \mathrm{O}$ ) and amide bond formation to prepare novel PAMAM conjugates containing agonists of the $\mathrm{P}_{2} \mathrm{Y}_{14}$ and the antiinflammatory $\mathrm{A}_{3}$ adenosine receptors (47).

\section{CuAAC Functionalization with non-Naturally Occurring Molecules}

CuAAC has been also used to attach non-naturally occurring molecules to the periphery of dendrimers. From a drug delivery perspective, ionic residues are interesting ligands that can lead to useful applications when presented onto multivalent scaffolds. For instance, cationic ligands

\section{Clicking Polymers for Drug Delivery}


are known to bind nucleic acids and result into gene delivery vehicles when multivalently displayed onto polymers and dendrimers (48). On the other hand, anionic polymers have been described as mimetics of glycosaminoglycans with applications in cancer therapy, as antiinflamatory agents, or inhibitors of amyloid aggregation (49). In addition, polyionic species have been used in the preparation of electrostatic complexes such as, micelles and assemblies with significant impact in biotechnology and drug delivery (50). In this context, the group of Fernandez-Megia and Riguera has reported the synthesis of anionic dendrimers by means of CuAAC (51). In a similar fashion to their previously described work on glycodendrimers (39, 40), azide-decorated GATG dendrimers and PEG-b-GATG block copolymers were functionalized under aqueous conditions with sulfated, sulfonated, and carboxylated alkynes $\left(\mathrm{CuSO}_{4}\right.$, ascorbate, $\left.t-\mathrm{BuOH}-\mathrm{H}_{2} \mathrm{O}\right)$. This $\mathrm{CuAAC}$ strategy was revealed more efficient than traditional coupling methods (such as amide and sulfation procedures) which usually result in non-homogeneous decoration patterns. Interestingly, incubation of a sulfated PEG- $b$-GATG copolymer of G3 with equimolecular amounts of an oppositely charged poly-L-Lysine (PLL) led to polyion complex (PIC) micelles as potential drug delivery systems. These micelles showed an improved stability compared to related systems from linear block copolymers (51). Similar CuAAC conditions have been more recently applied by Haag and coworkers for the anionic functionalization of dendritic polyglycerols that have been studied as L-selectin inhibitors (52).

In recent years, dendritic polymers carrying paramagnetic ions have found application as contrast agents (CA) in magnetic resonance imaging (MRI) (53). Particularly interesting is the use of these macromolecular $\mathrm{CA}$ in quantitative studies of microvessels and for prolonged angiographies, both of interest in cancer diagnosis. From a synthetic point of view, one of the

\section{Clicking Polymers for Drug Delivery}


major difficulties in the preparation of dendritic CA for MRI is their complete surface functionalization with metal chelates, which often leads to mixtures of compounds with varying degrees of substitution. This way, not only the advantage of starting from monodisperse materials is lost, but the final products become strongly batch-dependent. In this regard, the group of Fernandez-Megia and Riguera has recently reported the advantage of using CuAAC $\left(\mathrm{CuSO}_{4}\right.$, ascorbate, $\left.t-\mathrm{BuOH}-\mathrm{H}_{2} \mathrm{O}\right)$ for this goal by allowing the complete incorporation of preformed Gd chelates onto the dendritic surface of PEG- $b$-GATG block copolymers in very high yields (54). The analysis of the physical and pharmacokinetic properties in vitro and in vivo of this new family of dendritic CA revealed them as a promising platform for the development of CA for MRI.

The properties of PEG as antifouling agent to inhibit protein adhesion as well as for increasing the aqueous solubility and circulation times in the blood stream of covalently bound molecules/nanosystems are well known (55). Shabat and coworkers have reported the functionalization of self-immolative dendrimers with PEG by means of $\mathrm{CuAAC}\left(\mathrm{CuSO}_{4}, \mathrm{Cu}\right.$ wire, TBTA, DMF) to increase their water solubility and prevent aggregation under aqueous conditions $(56,57)$. A PEGylated dendritic pro-drug of G2 with four molecules of the anticancer agent camptothecin (CPT) was prepared and the release of the drug demonstrated by triggering with penicillin-G-amidase (Fig. 5). Cell-growth inhibition assays demonstrated increased toxicity of the dendritic pro-drug upon incubation with the enzyme.

Fig. 5 


\section{Periphery Functionalization by Click Chemistries other than CuAAC}

The above examples highlight the impact and utility of CuAAC in the synthesis and functionalization of dendrimers. It must be pointed out, however, that in some instances, $\mathrm{Cu}$ contamination might preclude the use of the final conjugates in biological systems (12). This has been illustrated by Weck and coworkers in the functionalization of azide-decorated PAMAM dendrimers with an alkynated PEG derivative (58). In this example, these authors demonstrated that the use of $\mathrm{CuSO}_{4} /$ ascorbate $/ t-\mathrm{BuOH}-\mathrm{H}_{2} \mathrm{O}$ as $\mathrm{CuAAC}$ coupling conditions resulted in dendrimers containing up to $5000 \mathrm{ppm}$ of $\mathrm{Cu}$, despite extensive purification protocols (extraction, dialysis, chromatography). The use of the ligand BPDS along with CuI allowed the authors to reduce the final $\mathrm{Cu}$ content down to $70 \mathrm{ppm}$, while substitution of $\mathrm{CuI}$ for a $\mathrm{Cu}$ wire showed a further decrease to only $40 \mathrm{ppm}$. In order to completely avoid $\mathrm{Cu}$ contamination in this case, the authors decided to move from $\mathrm{CuAAC}$ to the $\mathrm{Cu}$-free SPAAC alternative (11) by the use of a cyclooctyne-PEG derivative.

To the best of our knowledge, no relevant examples on the use of CuAAC for the conjugation of drugs to dendritic scaffolds have been reported up to date. On the other hand, alternative click reactions such as the formation of hydrazones and Michael addition are firmly established technologies for this goal. In a seminal report by the groups of Fréchet and Szoka, these authors described the use of hydrazone linkages to conjugate doxorubicin (DOX) onto PEGylated biodegradable Janus-type polyester (bow-tie) dendrimers (Fig. 6) (59). Interestingly, the hydrazone linkage not only provided a straightforward method for loading DOX, but it also allowed its controlled release under the acidic conditions at the endosome. Interestingly, while in vitro experiments showed the DOX-dendrimer conjugate to be 10 times less toxic than free DOX

\section{Clicking Polymers for Drug Delivery}


towards C-26 cultured cells, in vivo experiments in mice revealed improved circulation half-life (31 h vs $10 \mathrm{~min}$ ) and enhanced drug uptake (9 times higher) for the conjugate. Also, efficacy studies showed that a single intravenous injection of the DOX-dendrimer conjugate $(20 \mathrm{mg} / \mathrm{kg}$ DOX after 8 days of tumor implantation) caused complete tumor regression with a $100 \%$ survival of mice specimens over a 60-day experiment, in a similar fashion to FDA-approved liposomal drug carrier Doxil ${ }^{\circledR}$. Additional advantages of this bow-tie dendrimer conjugate are enhanced storage stability and ease of formulation.

Fig. 6

More recently, Haag and coworkers have relied on the Michael addition of thiols to maleimides for the conjugation of enzymatically cleavable anticancer pro-drugs onto dendritic polyglycerols (60). In this regard, self-immolative dendrimers based on para-aminobenzyloxycarbonyl coupled to Phe-Lys dipeptide or to D-Ala-Phe-Lys tripeptide were prepared and used for DOX and methotrexate conjugation, respectively. The selected peptide linkers were chosen based on their enzymatic cleavage by cathepsin B, a protease overexpressed in several tumor types. Evaluation of these dendrimer-drug conjugates revealed no beneficial effect for DOX upon culture with pancreatic or mammalian carcinoma tumor cell lines (probably as a result of inefficient cellular uptake), but substantial improvement in antiproliferative activity for the methotrexate-dendrimer conjugate.

\section{Clicking Polymers for Drug Delivery}




\section{SYNTHETIC POLYMERS}

The concept of click chemistry has been defined by Sharpless and coworkers over three main lines (3): (i) the production of properties through efficient transformations rather than challenging structures, (ii) the use of readily available starting materials, and (iii) the final materials should be easy to purify. Interestingly, these three same commandments have also been the driving force of polymer science since its very beginning. Indeed, polymer industry has prospered by manufacturing functional materials from easily accessible monomers using highly efficient chemical processes. It is not surprising therefore that polymer scientists have embraced the concept of click chemistry with enthusiasm, as reflected by the large number of reviews dealing with polymers and click procedures appeared in the literature since the original click report (14).

In the following sections, attention will be focused on the application of click chemistry for the synthesis and functionalization of linear, star, and branched polymers of interest in drug delivery. Examples dealing with the use of click procedures with polymeric nanosized DDS (which arise from the ability of polymers to aggregate in solution) have been already surveyed in a previous Expert Review (8) and hence are not covered herein.

\section{Polymer Synthesis: Linear Polymers}

The first examples of linear polymers prepared by CuAAC were published by Fokin, Finn, and coworkers (61) and by the group of van Maarseveen and Reek (62). These pioneering works within materials science (discovery of metal adhesives and fluorene-based conjugated polymers, respectively) were soon followed by a report from the group of Arora on the preparation of

\section{Clicking Polymers for Drug Delivery}


peptidomimetic oligomers, which represent the first biologically relevant polymers prepared by CuAAC (63). In this work, advantage was taken from the planar and polarized structure of triazols to prepare oligomers with similar properties to peptides but improved in vivo stability. Since that seminal work, several other groups have reported the preparation of a number of peptidomimetics by means of CuAAC (64).

Probably, the most important contribution to the field of drug delivery using linear polymers synthesized by CuAAC has been carried out by the group of Reineke $(65,66,67,68)$. In this series of reports, trehalose or cyclodextrin diazide monomers have been copolymerized with linear oligoamine monomers incorporating two terminal alkyne units (Fig. 7a). While the presence of carbohydrates was envisioned to grant biocompatibility, water solubility, and stability against aggregation, the oligoamine monomers facilitated DNA complexation and interaction with cell surfaces. Indeed, the carbohydrate-oligoamine copolymers prepared this way exhibited low cytotoxicity and facilitated a high cellular uptake and gene expression in HeLa and H9c2(2-1) cells.

Alternative click reactions traditionally employed in the preparation of synthetic polymers such as, Michael addition or the ring-opening of epoxides, have recently found application in interesting drug delivery programs. In an illustrative example, Rege, Kane, and coworkers have prepared a library of non-viral gene delivery vehicles via a combinatorial approach. By taking advantage of the clean reaction between the epoxide groups at diglycidyl ethers and the terminal amine groups at several linear oligoamines, a total of eighty copolymers were synthesized in parallel (69) (Fig. 7b). After primary screening and in vitro transfection, a polymer with

\section{Clicking Polymers for Drug Delivery}


significantly higher transfection activity and lower cytotoxicity than poly(ethylene imine) (PEI) could be identified.

Fig. 7

\section{Side Chain Functionalization of Polymers and Synthesis of Graft Copolymers}

The ability to efficiently prepare polymers functionalized at the side chains is considered of great importance in polymer science. A typical approach to this goal involves the preparation of "specialized" monomers, as those bearing carbohydrates or peptides of interest in biotechnology, for their subsequent polymerization. However, such a strategy has traditionally resulted troublesome or led to ill-defined monomeric species. In addition, the reactive functional groups typically found in carbohydrates and peptides often result incompatible with polymerization conditions or lead to undesired spontaneous polymerizations of the monomers. As a result, it is not surprising that the incorporation of different functionalities in a single polymer backbone has attracted the interest of polymer chemists during the last decade.

An alternative strategy for the functionalization of the side chains of polymers involves the polymerization of monomers carrying adequate handles for subsequent functionalization through efficient click processes. In this case, the selection of the click reaction results crucial to avoid again interference of the reactive handles with polymerization mechanisms, as early illustrated by the group of Binder when combining $\mathrm{CuAAC}$ and the ring-opening methathesis polymerization (ROMP) (70). All attempts to polymerize an alkynated 7-oxynorbornene

\section{Clicking Polymers for Drug Delivery}


derivative led to undesired broad molecular weight distributions, probably due to competing reactivity of the acetylene group with the ROMP catalyst.

The first successful polymerization and subsequent $\mathrm{CuAAC}$ side chain functionalization of a linear polymer that was reported without the need of intermediate activation steps was published by Emrick and coworkers in 2005 (71). Copolymers prepared from \&-caprolactone (CL) and $\alpha$-propargyl- $\delta$-valerolactone were successfully functionalized with an azide-containing PEG and RGD peptide under aqueous conditions $\left(\mathrm{CuSO}_{4}\right.$, ascorbate, acetone- $\left.\mathrm{H}_{2} \mathrm{O}, 80{ }^{\circ} \mathrm{C}\right)$. Interestingly, incubation of the resulting PEGylated graft copolymer $(5 \mathrm{mg} / \mathrm{mL})$ with $\mathrm{L} 929$ mouse fibroblast showed no qualitative change in cell monolayer morphology. In addition, the percentage of hemolysis of human red blood cells induced by the graft copolymer was comparable to that of the PEG precursor. Such results suggest a good biocompatibility for these amphiphilic copolymers, and highlight the potential of CuAAC for the functionalization of polymers for drug delivery and other bioapplications.

In addition to the above example, a range of different polymer backbones such as, polyoxazolines, polyisocyanides, and linear polypeptides among others, have been successfully functionalized using CuAAC (6). Among these polymers, those prepared via free radical polymerizations have received the greatest impact by the application of CuAAC. Pioneering work in this field has been done by Matyjaszewski and coworkers, in which monomers containing acetylene and azido groups were polymerized via ATRP (72). Interestingly, while poly(3-azidopropylmethacrylate) could be prepared with good control over polymerization, propargyl methacrylate (PMA) resulted in polymers with high polydispersity, multimodal molecular weight distributions, and cross-linked networks, probably due to an undesired

\section{Clicking Polymers for Drug Delivery}


participation of the alkyne group in the polymerization. In an effort to solve this inconvenience, Haddleton and coworkers decided to work with protected PMA monomers [3(trimethylsilyl)propargyl (TMS-PMA)] which after polymerization by ATRP, were deprotected and functionalized with $\alpha$-mannose and $\alpha$-galactose azido derivatives by $\mathrm{CuAAC}\left[\mathrm{Cu}\left(\mathrm{PPh}_{3}\right)_{3} \mathrm{Br}\right.$, $\left.\mathrm{Et}_{3} \mathrm{~N}, \mathrm{DMSO}\right]$ (73). The resulting glycopolymers showed a strong affinity for Con A and Ricinus Communis agglutinin lectins with affinities which depended on the density of the corresponding sugar, revealing the potential of this synthetic approach for the preparation of libraries of biologically relevant glycopolymers.

The polymerization of monomers incorporating unprotected alkyne groups via living radical polymerizations (LRP) still remains elusive, with very few examples reported in the literature $(74,75)$. A very elegant alternative to the use of protecting groups was reported by Haddleton, Mantovani, and coworkers in 2008 by means of a simultaneous CuAAC/ATRP of PMA using $\mathrm{CuBr} /$ iminopyridine as catalytic system for both reactions (Fig. 8a) (76). Interestingly, these authors found that the relative kinetics of CuAAC and ATRP could be tuned by the selection of the solvent, with the cycloaddition proceeding much faster than the polymerization in toluene or at equal rates in DMSO. In any case, the polydispersity indexes of the resulting polymers were in the range 1.1-1.3, in agreement with a controlled polymerization. Among the ligands that were attached by $\mathrm{CuAAC}$, it is worth to mention an unprotected azide functionalized mannose which reveals this approach with a promising future in drug delivery and other bioapplications, especially if aqueous reaction conditions were developed.

\section{Fig. 8}

\section{Clicking Polymers for Drug Delivery}


In a similar fashion, the group of Emrick has prepared polymeric phosphorylcholinecamptothecin conjugates via a one-pot ATRP/CuAAC protocol (77). These authors observed that under the conditions employed for the polymerization of methacryloyloxyethyl phosphorylcholine (MAPC) and TMS-PMA (CuBr, bipyridine, DMSO-MeOH), deprotection of the TMS groups occurred which allowed the in situ CuAAC functionalization of the polymer with various azido-functionalized CPT to yield statistic zwitterionic copolymers (Fig. 8b). These ionic drug-polymer conjugates showed excellent water solubility thanks to the unique properties of MAPC, with no aggregation being observed even at CPT loadings up to $14 \%$ in weight. In addition, the authors proved that the rate of drug release could be tailored by controlling the nature of the linker between the azide group and the CPT core. Interestingly, although $\mathrm{IC}_{50}$ values of these conjugates were higher than native CPT, the fact that the PMA-MAPC backbone showed no apparent toxicity envisages this strategy as an efficient approach in the design of water-soluble polymeric supports for the delivery of highly hydrophobic drugs.

As mentioned above, over the past decades several click reactions have been extensively employed for the side chain functionalization of polymers. Among them, the Michael addition of thiols to $\alpha, \beta$-unsaturated systems and the formation of hydrazones have received special attention in the drug delivery arena. As an exhaustive analysis of this literature falls outside the scope of this Expert Review, interested readers are referred to specialized reviews (78) (79). With regard to emerging click technologies, TEC has recently attracted most of the efforts of polymer chemists. The first successful example on the application of TEC for the side chain functionalization of polymers was reported by Schlaad and coworkers with polyoxazolines (80).

\section{Clicking Polymers for Drug Delivery}


The polymerization of 2-(3-butenyl)-2-oxazoline resulted mild enough to allow the complete preservation of the alkene groups which were subsequently functionalized via TEC (303 nm, THF-MeOH) in a very efficient way.

The intrinsic orthogonality displayed by click reactions can be exploited for the simultaneous decoration of polymers with different molecules of interest. This strategy pioneered by the group of Hawker in 2005 was initially tested for the dual functionalization of polymers via CuAAC and esterification reactions $\left[\mathrm{CuBr}\left(\mathrm{PPh}_{3}\right)_{3}\right.$, DIPEA, THF] (Fig. 9a) (81). Though the synthesis of esters does not comply with the click philosophy, this first report illustrated the advantage of combining precise chemistries in this field. Application of the same principle was later reported by Weck and coworkers for the simultaneous click functionalization of a poly(norbornene) with a nucleoside and biotin by means of $\mathrm{CuAAC}$ and hydrazone linkages $\left(\mathrm{CuSO}_{4}\right.$, ascorbate, DMF or DMSO, $\left.25^{\circ} \mathrm{C}\right)$ (Fig. 9b) (82).

Fig. 9

\section{End Group Functionalization of Polymers and Synthesis of Block Copolymers}

End-functionalized polymers constitute the starting point for the preparation of a wide variety of complex macromolecular architectures, including block, miktoarm, dendritic, and star polymers (83). Controlled living polymerizations allow the easy introduction of functional end groups into polymers, which have been exploited in subsequent click functionalizations. Not surprisingly, in the first example of a clicked block copolymer, advantage was taken of the combination of ATRP and CuAAC (84). The group of van Hest showed in 2005 that the bromine

\section{Clicking Polymers for Drug Delivery}


group of PS and poly(methyl methacrylate) (PMMA) prepared via ATRP could be easily transformed into azides by nucleophilic substitution. CuAAC coupling of the resulting polymers with one prepared from an alkynated ATRP initiator (CuBr, DBU, THF) led to the expected block copolymers (Fig. 10). This strategy allowed the preparation of a small library of block copolymers, some of them from PEG-N 3 and PEG-alkyne derivatives. In all cases, the formation of the block copolymer was shown to proceed to completion by IR and SEC. More recently, CuAAC has also been successfully combined to other polymerization techniques such as reversible addition-fragmentation chain transfer (RAFT) (85) and ring-opening polymerizations (86).

Fig. 10

The end group functionalization of linear polymers with functional molecules can be used as a means to achieve new properties. The first relevant example of this strategy with CuAAC in drug delivery was reported by Lutz and coworkers by functionalizing a poly(oligo(ethylene glycol) acrylate) (POEGA) obtained by ATRP with a GGRGDG hexapeptide (87). With this aim, an azide end group was first installed in POEGA by nucleophilic substitution and then reacted with an alkynated derivative of the hexapeptide by means of $\mathrm{CuAAC}[\mathrm{CuBr}$, bipyridine, NMP] (Fig. 11a). Unfortunately, no biological evaluation of the resulting conjugate was accomplished. In another interesting example, the group of Kakuchi exploited the end decoration of an azido-functionalized poly( $N$-isopropylacrylamide) (PNIPAM) with different small hydrophilic and hydrophobic alkynated molecules by $\mathrm{CuAAC}\left(\mathrm{CuSO}_{4}\right.$, ascorbate, THF- $\left.\mathrm{H}_{2} \mathrm{O}\right)$

\section{Clicking Polymers for Drug Delivery}


with the aim of tuning the characteristic lower critical solution temperature (LCST) of PNIPAM (around $32{ }^{\circ} \mathrm{C}$, depending on concentration and molecular weight) (

Fig. 11b) (88).

\section{Fig. 11}

The combination of orthogonal click technologies for the sequential functionalization of the end groups of heterotelechelic polymers appears as an attractive methodology for the preparation of complex structures such as triblocks and branched polymers. As a proof of concept, the group of Hawker was able to sequentially modify a PS bearing alkene and azide groups at the distal ends, by means of CuAAC (CuBr, PMDETA, THF) and TEC [UV light (365 nm), DMPA; or AIBN, $\left.80{ }^{\circ} \mathrm{C}\right](89)$. Functionalization was achieved starting from any of the end groups, in agreement with a complete orthogonality of the process (thermal thiol-ene conditions had to be employed to avoid azide decomposition under UV irradiation). A similar strategy based on Michael addition and TEC has been more recently described (90).

A further step towards the accelerated multifunctionalization of linear polymers has involved the implementation of simultaneous processes. Up to date, two protocols of this type have been reported for the preparation of block copolymers. Hizal, Tunca, and coworkers have described the combination of CuAAC and Diels-Alder for the preparation of PEG- $b$-PS- $b$ PMMA and PCL- $b$-PS- $b$-PMMA triblocks using a bifunctional PS as central block carrying anthracene and azide groups at the distal ends (CuBr, PMEDTA, DMF, $\left.120^{\circ} \mathrm{C}\right)$ (Fig. 12) (91).

\section{Clicking Polymers for Drug Delivery}


Application of the same methodology has more recently allowed the same authors to prepare a H-shaped quintopolymer from a central poly(tertbutylacrylate) (92).

\section{Fig. 12}

\section{Preparation and Functionalization of Cyclic Polymers}

One of the most challenging structures prepared via end group modification of linear polymers is undoubtedly that of cyclic polymers. The interest on cyclic polymers comes not only from their challenging structures, but also from their properties which are strongly influenced by that particular architecture. For instance, Szoka and coworkers showed that cyclic polymers have characteristic pharmacokinetic properties (93). Cyclic polyesters were prepared by copolymerization of $\alpha$-cholo- $\varepsilon$-caprolactone $(\alpha-\mathrm{Cl}-\varepsilon-\mathrm{CL})$ and $\varepsilon-\mathrm{CL}$, so that azide could be easily introduced at a later stage by nucleophilic displacement of the chlorine atom. CuAAC (CuI, $\mathrm{Et}_{3} \mathrm{~N}, \mathrm{THF}, 40^{\circ} \mathrm{C}$ ) was then used for the functionalization of these polymers with alkynated PEG chains (to improve water solubility) and a phenol derivative (for radiolabeling with ${ }^{125} \mathrm{I}$ ). It was revealed that cyclic constructs displayed longer plasma circulation times than the corresponding linear analogs, as the latter are able to traverse more easily the nanoporous structure of kidneys.

Clearly, cyclic polymers represent promising structures for the development of drug carriers with improved delivery attributes. In this regard, great efforts have been recently devoted for their preparation through click technologies. The group of Matyjaszewski had already reported cyclic PS as a side product during the step-growth CuAAC condensation of $\alpha$-alkyne- $\omega$ azide-PS (94). It was later demonstrated by the group of Grayson that the concentration of the

\section{Clicking Polymers for Drug Delivery}


polymer resulted to be a key factor for the preparation of the cyclic construct (95). By employing a continuous addition technique, these authors avoided the utilization of high dilution conditions, and cyclic PS up to 4200 Da could be efficiently prepared. In a more recent contribution, Monteiro and coworkers investigated the effect of polymer concentration and molecular weight, reaction temperature, feed rate, and $\mathrm{Cu}$ concentration on this cyclization reaction (96). An interesting alternative to the use of high dilution conditions or slow addition processes, in Fig. 13 is depicted an elegant preparation of cyclic polymers reported by the group of Chen and Liu that takes advantage of the unimer-micelle exchange equilibrium of thermo- and $\mathrm{pH}$-responsive polymers (97).

Fig. 13

\section{HYDROGELS}

Hydrogels are hydrophilic and three-dimensional polymeric networks capable of absorbing large amounts of water that have found extensive application in drug delivery (98). There are several examples on the use of click chemistry for the synthesis and functionalization of hydrogels.

\section{Michel Addition in the Preparation of Hydrogels}

Probably, the first report on this field came out from the group of Hubbel who used the Michael addition of thiols to methacrylates for the cross-linking of hydrophilic PEG polymers. The resulting gels were studied for the delivery of proteins, with BSA taken as a model (99). Again by the use of a Michael addition of thiols to vinyl sulfones, the group of Segura has been

\section{Clicking Polymers for Drug Delivery}


able to prepare PEG-based hydrogels for the delivery of DNA/PEI polyplexes to mesenchymal stem cells (MSC). This gene delivery approach was envisaged to promote the expression of tissue inductive factors locally (Fig. 14) (100). Since MSC express high levels of matrix metalloproteinase (MMP), MMP-degradable peptides were used as cross-linkers to allow cell migration through proteolytic degradation. In addition, RGD peptides were grafted to PEG to promote cell adhesion.

Fig. 14

\section{Diels-Alder Cycloaddition in the Preparation of Hydrogels}

An interesting feature of the Diels-Alder reaction comes from its reversibility at high temperatures, opening the door to self-healing biomaterials (101). In the early $1990 \mathrm{~s}$, the group of Saegusa described the use of furan and maleimide end-functionalized poly $(\mathrm{N}$ acetylethylimine) to prepare hydrogels $\left(\mathrm{CHCl}_{3}\right.$, room temperature) that could be gradually dissolved upon heating $\left(\mathrm{MeOH}-\mathrm{H}_{2} \mathrm{O}, 80^{\circ} \mathrm{C}\right)(102)$. In a related approach, Wei and coworkers have more recently reported the preparation of hydrogels between furan-functionalized dimethylacrylamide and bismaleimide-PEG under aqueous conditions (103). These authors showed that the resulting hydrogels were stable in water and that the gelation time was strongly dependent on temperature, which makes this an attractive approach for the preparation of smart injectable materials.

CuAAC and SPAAC in the Preparation of Hydrogels

\section{Clicking Polymers for Drug Delivery}


In recent years, the orthogonality and fast kinetics of $\mathrm{CuAAC}$ have attracted the attention of the hydrogel community. The first example of the use of CuAAC for the preparation of a hydrogel was reported by the group of Hilborn in 2006 (104). Poly(vinyl alcohol) (PVA) was modified either with azides or alkynes, producing two different polymers that yielded transparent hydrogels upon mixing in the presence of $\mathrm{CuSO}_{4}$ /ascorbate (Fig. 15a). Low degree of functionalization of the PVA backbone was required in order to maintain the water solubility of the building blocks. Altogether, this intermolecular cross-linking constitutes a promising alternative to traditional hydrogel preparations involving bifunctional low-molecular weight cross-linkers. As an example of this latter approach, Hedrick, Hawker, and coworkers reported the preparation of PEG-based hydrogels by CuAAC (Fig. 15b) (105). The high efficiency on the cross-linking rendered hydrogels with a more ideal structure (more even distribution of crosslink junctions) that resulted in larger cavities and improved properties (greater water adsorption, higher flexibility, enhanced tensile stress and tensile strain) compared to those prepared by conventional approaches such as photochemical cross-linking.

\section{Fig. 15}

One of the main problems associated to the preparation of hydrogels via $\mathrm{CuAAC}$ is the toxicity of $\mathrm{Cu}$. As a result, thorough hydrogel purifications are required to ensure complete removal of the metal catalyst. This critical purification step might seem, however, like a contradiction when gelation is performed in the presence of drugs (drug reservoir) or aqueous suspensions of cells (tissue engineering scaffolds) because of leaching. Illustrative examples in

\section{Clicking Polymers for Drug Delivery}


this field are those reported by the groups of Crescenzi in 2007 (106) and Dentini in 2009 (107) on the CuAAC mediated preparation of hydrogels from hyaluronic acid. While control hydrogels were extensively dialyzed against EDTA and water in order to remove the $\mathrm{Cu}$ catalyst, no purifications were performed when in the presence of model drugs (benzidamine and DOX) or Saccharomices cerevisiae yeast cells.

As an alternative to the use of $\mathrm{Cu}$ as catalyst, more benign alkyne-azide cycloaddition conditions for the preparation of gels have relied on the use of SPAAC. This Cu-free strategy has been exploited by the group of Turro for the in situ cross-linking of an azide-functionalized photodegradable star polymer with linkers carrying two cyclooctynes (Fig. 15c) (108). This strategy based on SPAAC was expected not only to open the door to complex, functional, and biocompatible networks, but also to allow better control of gelation than CuAAC. In addition, the anaerobic conditions required for similar gelations based on CuAAC $(109,110)$ were avoided in this case. Unfortunately, the selection of poly(tertbutylacrylate) as model scaffold required gelation to be performed in organic media, with no proof of drug delivery being accomplished (108). A step forward in the SPAAC preparation of biocompatible hydrogels has been more recently made by the group of Anseth, which has reported the preparation of PEG-based hydrogels under physiological conditions for the in situ encapsulation of 3 T3 fibroblasts (111, 112). In this case, the polymer network was constructed from a star PEG tetraazide that was cross-linked with a metalloproteinase cleavable peptide incorporating two terminal difluorocyclooctyne groups. In addition, alkene groups were introduced in the peptide backbone so that RGD peptides could be photopatterned onto the scaffold using TEC, in order to show control over cell growth. This way, two orthogonal and biocompatible click reactions were

\section{Clicking Polymers for Drug Delivery}


combined for the preparation of highly sophisticated materials mimicking the properties of the extracellular matrix (Fig. 16).

\section{Fig. 16}

\section{CONCLUSIONS}

The need of smart materials for the advance of drug delivery has resulted in polymers being designed for reducing the toxicity, increasing the absorption, and improving the release profile of drugs. At the same time, the inherent multivalency of polymers and dendrimers has been exploited for the incorporation of diverse functional molecules of interest in targeting and diagnosis. Polymeric hydrogels with the ability to encapsulate drugs and cells have also been developed for drug delivery and tissue engineering applications. In this context, the introduction of the click concept by Sharpless and coworkers in 2001, focusing the attention on modularity and orthogonality, has greatly benefited polymer synthesis, an area where reaction efficiency and product purity are significantly challenged. Indeed, click chemistry has revolutionized the synthesis of materials and refocused chemist's interests on the easy production of properties rather than on challenging structures. The efficiency related to click reactions has been embraced by researchers in different fields and inspired the publication of hundreds of papers in areas from materials and polymer science to nanotechnology and drug delivery.

Although initially, the $\mathrm{Cu}(\mathrm{I})$-catalyzed azide-alkyne cycloaddition (CuAAC) attracted most of the attention in the field, many other reactions (some of them firmly established before the click concept even being proposed) comply with the click philosophy. For example, this is the

\section{Clicking Polymers for Drug Delivery}


case of the Michael addition and Diels-Alder which have been traditionally used in drug delivery for decades. At the same time, the introduction of the click concept has attracted renewed interest on efficient classical transformations and the development of new reactions, such as the thiol-ene (TEC) and thiol-yne couplings (TYC).

Click chemistry has found in drug delivery an attractive test bank for bioconjugation. The requirement of multifunctionalized polymeric structures where selectively localizing drugs, targeting ligands, and imaging agents in precise proportions and sites has given the opportunity to assess the chemical orthogonality between functional groups and to serve as source of inspiration for the accelerated preparation/functionalization of complex macromolecular architectures. The possibility of clicking unprotected carbohydrates, peptides, and nucleotides of interest in drug delivery onto polymers and dendrimers has significantly accelerated the production of properties while reducing synthetic efforts. In the same way, click chemistry has given unprecedented access to complex copolymers and dendrimers from stoichiometric amounts of coupling partners. Cyclic polymers constitute another example of the efficiency of click chemistry in drug delivery. They represent promising structures for the creation of drug carriers with long plasma circulation times that can be now prepared with unprecedented fidelity thanks to click macrocyclization reactions. In addition, the planar and polarized structure of triazol linkages has been exploited for the preparation of CuAAC-based peptidomimetics with similar properties to peptides and improved in vivo stability. Although click reactions have been traditionally employed for the fabrication of biocompatible hydrogels, it has not been until recently that various orthogonal click reactions have been combined for the simultaneous preparation/functionalization of highly sophisticated hydrogels that mimic the properties of the

\section{Clicking Polymers for Drug Delivery}


extracellular matrix. This continuous feedback between drug delivery and click chemistry is expected to accelerate current delivery endeavors for the development of theranostics and complex multimodal agents. 
Lallana Page 36

\section{Acknowledgements}

This work was financially supported by the Spanish Ministry of Science and Innovation (CTQ2009-10963 and CTQ2009-14146-C02-02) and the Xunta de Galicia (10CSA209021PR and CN2011/037). 


\section{References}

1. A. S. Hoffman. The origins and evolution of "controlled" drug delivery systems. J. Contr. Rel. 132: 153-163 (2008).

2. B. M. Trost. Basic aspects of organic synthesis with transition metals. In (eds.), WileyVCH Verlag GmbH, 2008, pp. 2-14

3. H. C. Kolb, M. G. Finn and K. B. Sharpless. Click chemistry: Diverse chemical function from a few good reactions. Angew. Chem., Int. Ed. 40: 2004-2021 (2001).

4. $\quad \mathrm{P}$. Wu and V. V. Fokin. Catalytic azide-alkyne cycloaddition: Reactivity and applications. Aldrichimica Acta 40: 7-17 (2007).

5. M. Meldal and C. W. Tornøe. Cu-Catalyzed azide-alkyne cycloaddition. Chem. Rev. 108: 2952-3015 (2008).

6. R. K. Iha, K. L. Wooley, A. M. Nyström, D. J. Burke, M. J. Kade and C. J. Hawker. Applications of orthogonal "click" chemistries in the synthesis of functional soft materials. Chem. Rev. 109: 5620-5686 (2009).

7. M. van Dijk, D. T. S. Rijkers, R. M. J. Liskamp, C. F. van Nostrum and W. E. Hennink. Synthesis and applications of biomedical and pharmaceutical polymers via click chemistry methodologies. Bioconjugate Chem. 20: 2001-2016 (2009).

8. E. Lallana, A. Sousa-Herves, F. Fernandez-Trillo, R. Riguera and E. Fernandez-Megia. Click chemistry for drug delivery nanosystems. Pharm. Res. DOI: 10.1007/s1109511011-10568-11095

9. C. W. Tornøe, C. Christensen and M. Meldal. Peptidotriazoles on solid phase: $[1,2,3]-$ Triazoles by regiospecific copper(I)-catalyzed 1,3-dipolar cycloadditions of terminal alkynes to azides. J. Org. Chem. 67: 3057-3064 (2002).

10. V. V. Rostovtsev, L. G. Green, V. V. Fokin and K. B. Sharpless. A stepwise Huisgen cycloaddition process: Copper(I)-catalyzed regioselective "ligation" of azides and terminal alkynes. Angew. Chem., Int. Ed. 41: 2596-2599 (2002).

11. N. J. Agard, J. A. Prescher and C. R. Bertozzi. A strain-promoted [3+2] azide-alkyne cycloaddition for covalent modification of biomolecules in living systems. J. Am. Chem. Soc. 126: 15046-15047 (2004).

12. E. Lallana, R. Riguera and E. Fernandez-Megia. Reliable and efficient procedures for the conjugation of biomolecules through Huisgen azide-alkyne cycloadditions. Angew. Chem. Int. Ed. 50: 8794-8804 (2011).

13. G. S. Kwon. Polymeric drug delivery systems Taylor \& Francis, 2005.

14. C. Barner-Kowollik, F. E. DuPrez, P. Espeel, C. J. Hawker, T. Junkers, H. Schlaad and W. Van Camp. "Clicking" polymers or just efficient linking: What is the difference? Angew. Chem. Int. Ed. 50: 60-62 (2011).

15. D. Astruc, E. Boisselier and C. Ornelas. Dendrimers designed for functions: From physical, photophysical, and supramolecular properties to applications in sensing, catalysis, molecular electronics, photonics, and nanomedicine. Chem. Rev. 110: 18571959 (2010).

16. C. C. Lee, J. A. MacKay, J. M. J. Fréchet and F. C. Szoka. Designing dendrimers for biological applications. Nat. Biotechnol. 23: 1517-1526 (2005).

\section{Clicking Polymers for Drug Delivery}


17. D. A. Tomalia, H. Baker, J. Dewald, M. Hall, G. Kallos, S. Martin, J. Roeck, J. Ryder and P. Smith. A new class of polymers: Starburst-dendritic macromolecules. Polym. J. 17: 117-132 (1985).

18. E. M. M. de Brabander-van den Berg and E. W. Meijer. Poly(propylene imine) dendrimers: Large-scale synthesis by hetereogeneously catalyzed hydrogenations. Angew. Chem., Int. Ed. Engl. 32: 1308-1311 (1993).

19. R. Haag, A. Sunder and J.-F. Stumbe. An approach to glycerol dendrimers and pseudodendritic polyglycerols. J. Am. Chem. Soc. 122: 2954-2955 (2000).

20. P. Wu, A. K. Feldman, A. K. Nugent, C. J. Hawker, A. Scheel, B. Voit, J. Pyun, J. M. J. Frechet, K. B. Sharpless and V. V. Fokin. Efficiency and fidelity in a click-chemistry route to triazole dendrimers by the copper(I)-catalyzed ligation of azides and alkynes. Angew. Chem., Int. Ed. 43: 3928-3932 (2004).

21. C. J. Hawker and J. M. J. Fréchet. Preparation of polymers with controlled molecular architecture. A new convergent approach to dendritic macromolecules. J. Am. Chem. Soc. 112: $7638-7647$ (1990).

22. M. J. Joralemon, R. K. O'Reilly, J. B. Matson, A. K. Nugent, C. J. Hawker and K. L. Wooley. Dendrimers clicked together divergently. Macromolecules 38: 5436-5443 (2005).

23. P. Wu, M. Malkoch, J. N. Hunt, R. Vestberg, E. Kaltgrad, M. G. Finn, V. V. Fokin, K. B. Sharpless and C. J. Hawker. Multivalent, bifunctional dendrimers prepared by click chemistry. Chem. Commun. 5775-5777 (2005).

24. M. M. Kose, G. Yesilbag and A. Sanyal. Segment block dendrimers via Diels-Alder cycloaddition. Org. Lett. 10: 2353-2356 (2008).

25. P. Antoni, Y. Hed, A. Nordberg, D. Nyström, H. von Holst, A. Hult and M. Malkoch. Bifunctional dendrimers: From robust synthesis and accelerated one-pot postfunctionalization strategy to potential applications. Angew. Chem., Int. Ed. 48: 21262130 (2009).

26. K. L. Killops, L. M. Campos and C. J. Hawker. Robust, efficient, and orthogonal synthesis of dendrimers via thiol-ene "click" chemistry. J. Am. Chem. Soc. 130: 50625064 (2008).

27. G. Chen, J. Kumar, A. Gregory and M. H. Stenzel. Efficient synthesis of dendrimers via a thiol-yne and esterification process and their potential application in the delivery of platinum anti-cancer drugs. Chem. Commun. 6291-6293 (2009).

28. T. Kang, R. J. Amir, A. Khan, K. Ohshimizu, J. N. Hunt, K. Sivanandan, M. I. Montañez, M. Malkoch, M. Ueda and C. J. Hawker. Facile access to internally functionalized dendrimers through efficient and orthogonal click reactions. Chem. Commun. 46: 15561558 (2010).

29. R. J. Amir, L. Albertazzi, J. Willis, A. Khan, T. Kang and C. J. Hawker. Multifunctional trackable dendritic scaffolds and delivery agents. Angew. Chem. Int. Ed. 50: 3425-3429 (2011).

30. L. Brauge, G. Magro, A. M. Caminade and J. P. Majoral. First divergent strategy using two AB2 unprotected monomers for the rapid synthesis of dendrimers. J. Am. Chem. Soc. 123: 6698-6699 (2001).

\section{Clicking Polymers for Drug Delivery}


31. V. Maraval, A. M. Caminade, J. P. Majoral and J. C. Blais. Dendrimer design: How to circumvent the dilemma of a reduction of steps or an increase of function multiplicity? Angew. Chem. Int. Ed. 42: 1822-1826 (2003).

32. P. Antoni, D. Nyström, C. J. Hawker, A. Hult and M. Malkoch. A chemoselective approach for the accelerated synthesis of well-defined dendritic architectures. Chem. Commun. 2249-2251 (2007).

33. A. Vieyres, T. Lam, R. Gillet, G. Franc, A. Castonguay and A. Kakkar. Combined CuIcatalysed alkyne-azide cycloaddition and furan-maleimide Diels-Alder "click" chemistry approach to thermoresponsive dendrimers. Chem. Commun. 46: 1875-1877 (2010).

34. P. Antoni, M. J. Robb, L. Campos, M. Montanez, A. Hult, E. Malmström, M. Malkoch and C. J. Hawker. Pushing the limits for thiol-ene and CuAAC reactions: Synthesis of a 6th generation dendrimer in a single day. Macromolecules 43: 6625-6631 (2010).

35. M. Malkoch, K. Schleicher, E. Drockenmuller, C. J. Hawker, T. P. Russell, P. Wu and V. V. Fokin. Structurally diverse dendritic libraries: A highly efficient functionalization approach using click chemistry. Macromolecules 38: 3663-3678 (2005).

36. H.-J. Gabius. The sugar code: Fundamentals of glycosciences Wiley-Blackwell, Weinheim, 2009.

37. A. Imberty, Y. M. Chabre and R. Roy. Glycomimetics and glycodendrimers as high affinity microbial anti-adhesins. Chem. Eur. J. 14: 7490-7499 (2008).

38. J. A. F. Joosten, N. T. H. Tholen, F. Ait El Maate, A. J. Brouwer, G. Wilma Van Esse, D. T. S. Rijkers, R. M. J. Liskamp and R. J. Pieters. High-yielding microwave-assisted synthesis of triazole-linked glycodendrimers by copper-catalyzed [3+2] cycloaddition. Eur. J. Org. Chem. 70: 3182-3185 (2005).

39. E. Fernandez-Megia, J. Correa, I. Rodríguez-Meizoso and R. Riguera. A click approach to unprotected glycodendrimers. Macromolecules 39: 2113-2120 (2006).

40. E. Fernandez-Megia, J. Correa and R. Riguera. "Clickable" PEG-dendritic block copolymers. Biomacromolecules 7: 3104-3111 (2006).

41. E. M. Muñoz, J. Correa, E. Fernandez-Megia and R. Riguera. Probing the relevance of lectin clustering for the reliable evaluation of multivalent carbohydrate recognition. $J$. Am. Chem. Soc. 131: 17765-17767 (2009).

42. J. S. Desgrosellier and D. A. Cheresh. Integrins in cancer: biological implications and therapeutic opportunities. Nat. Rev. Cancer 10: 9-22 (2010).

43. D. T. S. Rijkers, G. W. Van Esse, R. Merkx, A. J. Brouwer, H. J. F. Jacobs, R. J. Pieters and R. M. J. Liskamp. Efficient microwave-assisted synthesis of multivalent dendrimeric peptides using cycloaddition reaction (click) chemistry. Chem. Commun. 4581-4583 (2005).

44. I. Dijkgraaf, A. Y. Rijnders, A. Soede, A. C. Dechesne, G. W. van Esse, A. J. Brouwer, F. H. M. Corstens, O. C. Boerman, D. T. S. Rijkers and R. M. J. Liskamp. Synthesis of DOTA-conjugated multivalent cyclic-RGD peptide dendrimers via 1,3-dipolar cycloaddition and their biological evaluation: Implications for tumor targeting and tumor imaging purposes. Org. Biomol. Chem. 5: 935-944 (2007).

45. R. J. Pieters, D. T. S. Rijkers and R. M. J. Liskamp. Application of the 1,3-dipolar cycloaddition reaction in chemical biology: Approaches toward multivalent

\section{Clicking Polymers for Drug Delivery}


Lallana Page 40

carbohydrates and peptides and peptide-based polymers. QSAR \& Combinatorial Science 26: 1181-1190 (2007).

46. S. de Castro, H. Maruoka, K. Hong, S. M. Kilbey, S. Costanzi, B. Hechler, G. G. Brown Jr, C. Gachet, T. K. Harden and K. A. Jacobson. Functionalized congeners of P2Y 1 receptor antagonists: 2-Alkynyl (N)-methanocarba 2'-deoxyadenosine 3',5'-bisphosphate analogues and conjugation to a polyamidoamine (PAMAM) dendrimer carrier. Bioconjugate Chem. 21: 1190-1205 (2010).

47. D. K. Tosh, L. S. Yoo, M. Chinn, K. Hong, S. M. Kilbey II, M. O. Barrett, I. P. Fricks, T. K. Harden, Z.-G. Gao and K. A. Jacobson. Polyamidoamine (PAMAM) dendrimer conjugates of "clickable" agonists of the $\mathrm{A}_{3}$ adenosine receptor and coactivation of the P2Y 14 receptor by a tethered nucleotide. Bioconjugate Chem. 21: 372-384 (2010).

48. C. Dufès, I. F. Uchegbu and A. G. Schätzlein. Dendrimers in gene delivery. Adv. Drug. Del. Rev. 57: 2177-2202 (2005).

49. N. Volpi. Therapeutic applications of glycosaminoglycans. Curr. Med. Chem. 13 (15) 1799-1810 (2006).

50. Y. Lee and K. Kataoka. Biosignal-sensitive polyion complex micelles for the delivery of biopharmaceuticals. Soft Matter 5: 3810-3817 (2009).

51. A. Sousa-Hervés, E. Fernandez-Megia and R. Riguera. Synthesis and supramolecular assembly of clicked anionic dendritic polymers into polyion complex micelles. Chem. Commun. 3136-3138 (2008).

52. M. Weinhart, D. Gröger, S. Enders, J. Dernedde and R. Haag. Synthesis of dendritic polyglycerol anions and their efficiency toward L-selectin inhibition. Biomacromolecules 12: 2502-2511 (2011).

53. A. J. L. Villaraza, A. Bumb and M. W. Brechbiel. Macromolecules, dendrimers, and nanomaterials in magnetic resonance imaging: The interplay between size, function, and pharmacokinetics. Chem. Rev. 110: 2921-2959 (2010).

54. F. Fernández-Trillo, J. Pacheco-Torres, J. Correa, P. Ballesteros, P. Lopez-Larrubia, S. Cerdán, R. Riguera and E. Fernandez-Megia. Dendritic MRI contrast agents: An efficient prelabeling approach based on CuAAC. Biomacromolecules 12: 2902-2907 (2011).

55. F. M. Veronese and G. Pasut. PEGylation, successful approach to drug delivery. Drug Discovery Today 10: 1451-1458 (2005).

56. A. Gopin, S. Ebner, B. Attali and D. Shabat. Enzymatic activation of second-generation dendritic prodrugs: Conjugation of self-immolative dendrimers with poly(ethylene glycol) via click chemistry. Bioconjugate Chem. 17: 1432-1440 (2006).

57. R. J. Amir, E. Danieli and D. Shabat. Receiver-amplifier, self-immolative dendritic device. Chem. Eur. J. 13: 812-821 (2007).

58. C. Ornelas, J. Broichhagen and M. Weck. Strain-promoted alkyne azide cycloaddition for the functionalization of poly(amide)-based dendrons and dendrimers. J. Am. Chem. Soc. 132: 3923-3931 (2010).

59. C. C. Lee, E. R. Gillies, M. E. Fox, S. J. Guillaudeu, J. M. J. Fréchet, E. E. Dy and F. C. Szoka. A single dose of doxorubicin-functionalized bow-tie dendrimer cures mice bearing C-26 colon carcinomas. Proc. Natl. Acad. Sci. U.S.A. 103: 16649-16654 (2006).

\section{Clicking Polymers for Drug Delivery}


60. M. Calderón, R. Graeser, F. Kratz and R. Haag. Development of enzymatically cleavable prodrugs derived from dendritic polyglycerol. Bioorg. Med. Chem. Lett. 19: 3725-3728 (2009).

61. D. D. Diaz, S. Punna, P. Holzer, A. K. McPherson, K. B. Sharpless, V. V. Fokin and M. G. Finn. Click chemistry in materials synthesis. 1. Adhesive polymers from coppercatalyzed azide-alkyne cycloaddition. J. Polym. Sci., Part A: Polym. Sci. 42: 4392-4403 (2004).

62. D. J. V. C. v. Steenis, O. R. P. David, G. P. F. v. Strijdonck, J. H. v. Maarseveen and J. N. H. Reek. Click-chemistry as an efficient synthetic tool for the preparation of novel conjugated polymers. Chem. Commun. 4333-4335 (2005).

63. N. G. Angelo and P. S. Arora. Nonpeptidic Foldamers from Amino Acids: Synthesis and characterization of 1,3-substituted triazole oligomers. J. Am. Chem. Soc. 127: 1713417135 (2005).

64. Y. L. Angell and K. Burgess. Peptidomimetics via copper-catalyzed azide-alkyne cycloadditions. Chem. Soc. Rev. 36: 1674-1689 (2007).

65. S. Srinivasachari, Y. Liu, G. Zhang, L. Prevette and T. M. Reineke. Trehalose Click polymers inhibit nanoparticle aggregation and promote pDNA delivery in serum. J. Am. Chem. Soc. 128: 8176-8184 (2006).

66. S. Srinivasachari, Y. Liu, L. E. Prevette and T. M. Reineke. Effects of trehalose click polymer length on pDNA complex stability and delivery efficacy. Biomaterials 28: 28852898 (2007).

67. S. Srinivasachari and T. M. Reineke. Versatile supramolecular pDNA vehicles via "click polymerization" of $\beta$-cyclodextrin with oligoethyleneamines. Biomaterials 30: 928-938 (2009).

68. L. E. Prevette, M. L. Lynch, K. Kizjakina and T. M. Reineke. Correlation of amine number and pDNA binding mechanism for trehalose-based polycations. Langmuir 24: 8090-8101 (2008).

69. S. Barua, A. Joshi, A. Banerjee, D. Matthews, S. T. Sharfstein, S. M. Cramer, R. S. Kane and K. Rege. Parallel synthesis and screening of polymers for non-viral gene delivery. Mol. Pharmaceutics 6: 86-97 (2008).

70. W. H. Binder and C. Kluger. Combining ring-opening metathesis polymerization (ROMP) with Sharpless-type 'click' reactions: An easy method for the preparation of side chain functionalized poly(oxynorbornenes). Macromolecules 37: 9321-9330 (2004).

71. B. Parrish, R. B. Breitenkamp and T. Emrick. PEG- and peptide-grafted aliphatic polyesters by click chemistry. J. Am. Chem. Soc. 127: 7404-7410 (2005).

72. B. S. Sumerlin, N. V. Tsarevsky, G. Louche, R. Y. Lee and K. Matyjaszewski. Highly efficient "click" functionalization of poly(3-azidopropyl methacrylate) prepared by ATRP. Macromolecules 38: 7540-7545 (2005).

73. V. Ladmiral, G. Mantovani, G. J. Clarkson, S. Cauet, J. L. Irwin and D. M. Haddleton. Synthesis of neoglycopolymers by a combination of "click chemistry" and living radical polymerization. J. Am. Chem. Soc. 128: 4823-4830 (2006).

74. X. Zhang, X. Lian, L. Liu, J. Zhang and H. Zhao. Synthesis of comb copolymers with pendant chromophore groups based on RAFT polymerization and click chemistry and

\section{Clicking Polymers for Drug Delivery}


formation of electron donor-acceptor supramolecules. Macromolecules 41: 7863-7869 (2008).

75. W. Zhang, W. Zhang, Z. Zhang, J. Zhu and X. Zhu. SET-RAFT polymerization of progargyl methacrylate and a one-pot/one-step preparation of side-chain functionalized polymers via combination of SET-RAFT and click chemistry. Macromol. Rapid Commun. 31: 1354-1358 (2010).

76. J. Geng, J. Lindqvist, G. Mantovani and D. M. Haddleton. Simultaneous copper(I)catalyzed azide-alkyne cycloaddition (CuAAC) and living radical polymerization. Angew. Chem., Int. Ed. 47: 4180-4183 (2008).

77. X. Chen, S. McRae, S. Parelkar and T. Emrick. Polymeric phosphorylcholinecamptothecin conjugates prepared by controlled free radical polymerization and click chemistry. Bioconjugate Chem. 20: 2331-2341 (2009).

78. B. D. Mather, K. Viswanathan, K. M. Miller and T. E. Long. Michael addition reactions in macromolecular design for emerging technologies. Prog. Polym. Sci. 31: 487-531 (2006).

79. K. Ulbrich and V. Subr. Polymeric anticancer drugs with $\mathrm{pH}$-controlled activation. $A d v$. Drug. Del. Rev. 56: 1023-1050 (2004).

80. A. Gress, A. Volkel and H. Schlaad. Thio-click modification of poly[2-(3-butenyl)-2oxazoline]. Macromolecules 40: 7928-7933 (2007).

81. M. Malkoch, R. J. Thibault, E. Drockenmuller, M. Messerschmidt, B. Voit, T. P. Russell and C. J. Hawker. Orthogonal approaches to the simultaneous and cascade functionalization of macromolecules using click chemistry. J. Am. Chem. Soc. 127: 14942-14949 (2005).

82. S. K. Yang and M. Weck. Modular Covalent multifunctionalization of copolymers. Macromolecules 40: 346-351 (2007).

83. D. Taton and Y. Gnanou. Guidelines for synthesizing block copolymers. In (eds.), WileyVCH Verlag GmbH \& Co., 2008, pp. 9-38

84. J. A. Opsteen and J. C. M. van Hest. Modular synthesis of block copolymers via cycloaddition of terminal azide and alkyne functionalized polymers. Chem. Commun. 5759 (2005).

85. D. Quémener, T. P. Davis, C. Barner-Kowollik and M. H. Stenzel. RAFT and click chemistry: A versatile approach to well-defined block copolymers. Chem. Commun. 5051-5053 (2006).

86. W. Agut, D. Taton and S. Lecommandoux. A versatile synthetic approach to polypeptide based rod-coil block copolymers by click chemistry. Macromolecules 40: $5653-5661$ (2007).

87. J. F. Lutz, H. G. Börner and K. Weichenhan. Combining ATRP and "click" chemistry: A promising platform toward functional biocompatible polymers and polymer bioconjugates. Macromolecules 39: 6376-6383 (2006).

88. A. Narumi, K. Fuchise, R. Kakuchi, A. Toda, T. Satoh, S. Kawaguchi, K. Sugiyama, A. Hirao and T. Kakuchi. A versatile method for adjusting thermoresponsivity: Synthesis and "click" reaction of an azido end-functionalized poly( $N$-isopropylacrylamide). Macromol. Rapid Commun. 29: 1126-1133 (2008).

\section{Clicking Polymers for Drug Delivery}


89. L. M. Campos, K. L. Killops, R. Sakai, J. M. J. Paulusse, D. Damiron, E. Drockenmuller, B. W. Messmore and C. J. Hawker. Development of thermal and photochemical strategies for thiol-ene click polymer functionalization. Macromolecules 41: 7063-7070 (2008).

90. B. Yu, J. W. Chan, C. E. Hoyle and A. B. Lowe. Sequential thiol-ene/thiol-ene and thiolene/thiol-yne reactions as a route to well-defined mono and bis end-functionalized poly(N-isopropylacrylamide). J. Polym. Sci., Part A: Polym. Sci. 47: 3544-3557 (2009).

91. H. Durmaz, A. Dag, O. Altintas, T. Erdogan, G. Hizal and U. Tunca. One-pot synthesis of ABC type triblock copolymers via in situ click [3 + 2] and Diels-Alder [4 + 2] reactions. Macromolecules 40: 191-198 (2007).

92. E. Gungor, G. Hizal and U. Tunca. One-pot double click reactions for the preparation of H-shaped ABCDE-type quintopolymer. J. Polym. Sci., Part A: Polym. Sci. 47: 34093418 (2009).

93. N. Nasongkla, B. Chen, N. Macaraeg, M. E. Fox, J. M. J. Fréchet and F. C. Szoka. Dependence of pharmacokinetics and biodistribution on polymer architecture: Effect of cyclic versus linear polymers. J. Am. Chem. Soc. 131: 3842-3843 (2009).

94. N. V. Tsarevsky, B. S. Sumerlin and K. Matyjaszewski. Step-growth "click" coupling of telechelic polymers prepared by atom transfer radical polymerization. Macromolecules 38: 3558-3561 (2005).

95. B. A. Laurent and S. M. Grayson. An efficient route to well-defined macrocyclic polymers via "click" cyclization. J. Am. Chem. Soc. 128: 4238-4239 (2006).

96. D. E. Lonsdale, C. A. Bell and M. J. Monteiro. Strategy for rapid and high-purity monocyclic polymers by CuAAC "click" reactions. Macromolecules 43: 3331-3339 (2010).

97. Z. Ge, Y. Zhou, J. Xu, H. Liu, D. Chen and S. Liu. High-efficiency preparation of macrocyclic diblock copolymers via selective click reaction in micellar media. J. Am. Chem. Soc. 131: 1628-1629 (2009).

98. T. R. Hoare and D. S. Kohane. Hydrogels in drug delivery: Progress and challenges. Polymer 49: 1993-2007 (2008).

99. D. L. Elbert, A. B. Pratt, M. P. Lutolf, S. Halstenberg and J. A. Hubbell. Protein delivery from materials formed by self-selective conjugate addition reactions. J. Contr. Rel. 76: 11-25 (2001).

100. Y. Lei and T. Segura. DNA delivery from matrix metalloproteinase degradable poly(ethylene glycol) hydrogels to mouse cloned mesenchymal stem cells. Biomaterials 30: 254-265 (2009).

101. A. B. W. Brochu, S. L. Craig and W. M. Reichert. Self-healing biomaterials. J. Biomed. Mater. Res., Part A 96A: 492-506 (2011).

102. Y. Chujo, K. Sada and T. Saegusa. Reversible gelation of polyoxazoline by means of Diels-Alder reaction. Macromolecules 23: 2636-2641 (1990).

103. H.-L. Wei, Z. Yang, L.-M. Zheng and Y.-M. Shen. Thermosensitive hydrogels synthesized by fast Diels-Alder reaction in water. Polymer 50: 2836-2840 (2009).

104. D. A. Ossipov and J. Hilborn. Poly(vinyl alcohol)-based hydrogels formed by "click chemistry". Macromolecules 39: 1709-1718 (2006).

\section{Clicking Polymers for Drug Delivery}


105. M. Malkoch, R. Vestberg, N. Gupta, L. Mespouille, P. Dubois, A. F. Mason, J. L. Hedrick, Q. Liao, C. W. Frank, K. Kingsbury and C. J. Hawker. Synthesis of welldefined hydrogel networks using click chemistry. Chem. Commun. 2774-2776 (2006).

106. V. Crescenzi, L. Cornelio, C. Di Meo, S. Nardecchia and R. Lamanna. Novel hydrogels via click chemistry: Synthesis and potential biomedical applications. Biomacromolecules 8: $1844-1850$ (2007).

107. G. Testa, C. Di Meo, S. Nardecchia, D. Capitani, L. Mannina, R. Lamanna, A. Barbetta and M. Dentini. Influence of dialkyne structure on the properties of new click-gels based on hyaluronic acid. Int. J. Pharm. 378: 86-92 (2009).

108. J. A. Johnson, J. M. Baskin, C. R. Bertozzi, J. T. Koberstein and N. J. Turro. Copper-free click chemistry for the in situ crosslinking of photodegradable star polymers. Chem. Commun. 3064-3066 (2008).

109. J. A. Johnson, D. R. Lewis, D. D. Diaz, M. G. Finn, J. T. Koberstein and N. J. Turro. Synthesis of degradable model networks via ATRP and click chemistry. J. Am. Chem. Soc. 128: 6564-6565 (2006).

110. J. A. Johnson, M. G. Finn, J. T. Koberstein and N. J. Turro. Synthesis of photocleavable linear macromonomers by ATRP and star macromonomers by a tandem ATRP-click reaction: Precursors to photodegradable model networks. Macromolecules 40: 3589-3598 (2007).

111. C. A. DeForest, B. D. Polizzotti and K. S. Anseth. Sequential click reactions for synthesizing and patterning three-dimensional cell microenvironments. Nat Mater 8: 659664 (2009).

112. C. A. DeForest, E. A. Sims and K. S. Anseth. Peptide-functionalized click hydrogels with independently tunable mechanics and chemical functionality for 3D cell culture. Chem.

Mat. 22: 4783-4790 (2010). 


\section{Figure Legends}

Fig. $1 \mathrm{Cu}(\mathrm{I})$-chelating ligands for $\mathrm{CuAAC}$ commonly employed in bioconjugation. [BPDS (bathophenanthroline disulphonated disodium salt); TBTA [tris(benzyltriazolylmethyl)amine]; THPTA [tris(hydroxypropyltriazolylmethyl)amine]].

Fig. 2 Representative examples of bifunctional dendrimers. Adapted with permission from a) ref. (23); b) ref. (24); and c) ref. (25).

Fig. 3 Repeating units employed in the accelerated preparation of dendrimers: Adapted with permission from a) ref. $(30,31)$; b) ref. (32); c) ref. (33); and d) ref. (34).

Fig. $4 \mathrm{CuAAC}$ decoration of dendrimers with unprotected carbohydrates and increased affinity in multivalent carbohydrate recognition as a function of generation and lectin density. Adapted with permission from ref. (39) and (41).

Fig. 5 Structure of a PEGylated (purple), self-immolative, dendritic CPT (blue) pro-drug with a trigger (red) designed for activation by penicillin-G-amidase. Reproduced with permission from ref. (56).

Fig. 6 Functionalization of a PEGylated bow-tie dendrimer with DOX by means of hydrazone linkages. [PEO [poly(ethylenoxide)]; TFA (trifluoroacetic acid)]. Adapted with permission from ref. (59).

Clicking Polymers for Drug Delivery 
Fig. 7 a) Linear carbohydrate-oligoamine polymers prepared by $\mathrm{CuAAC}$ as gene delivery vehicles. b) Schematic representation of the preparation of a library of cationic polymers prepared by ring-opening of diglycidyl ethers by primary amines. Adapted with permission from a) ref. $(65,67)$; and b) ref. (69).

Fig. 8 Representative examples of CuAAC/ATRP protocols. Adapted with permission from a) ref. (76); and b) ref. (77).

Fig. 9 Multifunctionalization of linear polymers by simultaneous click reactions. [DMT (dimethoxytrityl)]. Adapted with permission from a) ref. (81); and b) ref. (82).

Fig. 10 Preparation of linear block copolymers by means of a combination of ATRP and CuAAC. Adapted with permission from ref. (84).

Fig. 11 a) End group functionalization of POEGA with a RGD peptide by means of CuAAC. b) Synthesis and effect of end group on the LCST of a library of PNIPAM derivatives. Adapted with permission from a) ref. (87); and b) ref. (88).

Fig. 12 Schematic representation of a triblock copolymer synthesis by means of simultaneous CuAAC and Diels-Alder reactions. Adapted with permission from ref. (91).

\section{Clicking Polymers for Drug Delivery}


Fig. 13 Highly efficient preparation of macrocyclic diblock copolymers via combination of supramolecular self-assembly and intramolecular CuAAC ring closure. Reproduced with permission from ref. (97).

Fig. 14 Schematic representation of the preparation of PEG-based hydrogels containing matrix metalloproteinase sensitive peptides $(\mathrm{MMPxl})$ as linkers and their use for the delivery of polyplexes to MSC. Reproduced with permission from ref. (100).

Fig. 15 Representative examples of CuAAC and SPAAC for the preparation of hydrogels. Adapted with permission from a) ref. (104); b) ref. (105); and c) ref. (108).

Fig. 16 Macromolecular precursors react through SPAAC allowing for the direct encapsulation of cells within click hydrogels. The presence of terminal alkenes in this three-dimensional network enables patterning of biological functionalities in real time and with micrometer-scale resolution by means of an orthogonal thiol-ene photocoupling reaction (shown for three fluorescently labeled peptides using stereolithography). Adapted with permission from ref. (111) and (112). 
Lallana Page 48

Figures

2
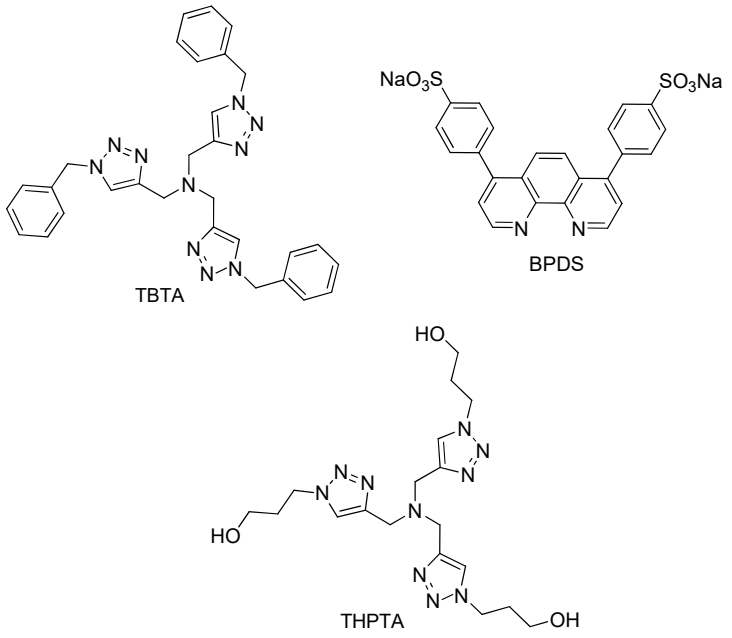

3

Figure 1

4

Clicking Polymers for Drug Delivery 


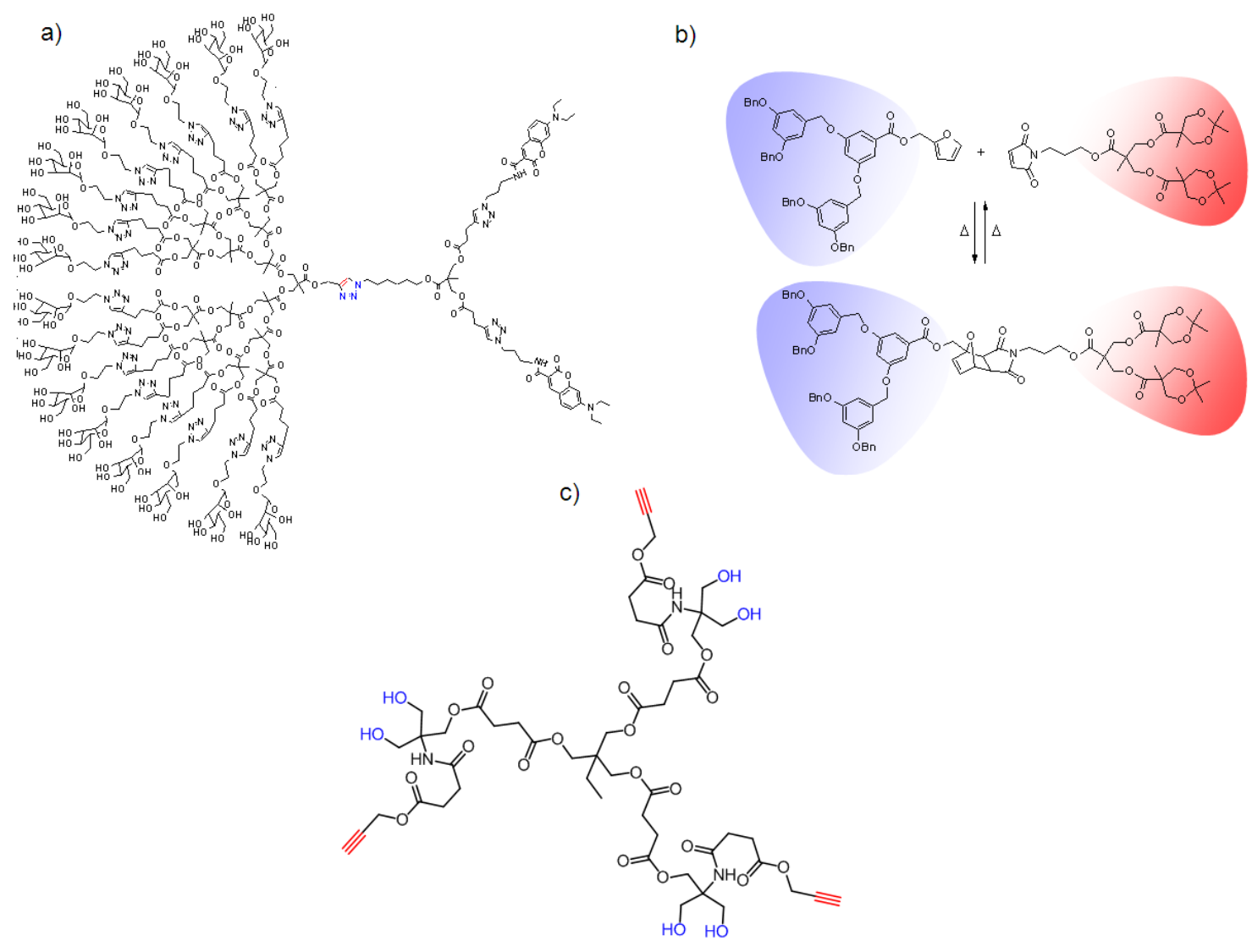

Figure 2 
Lallana Page 50
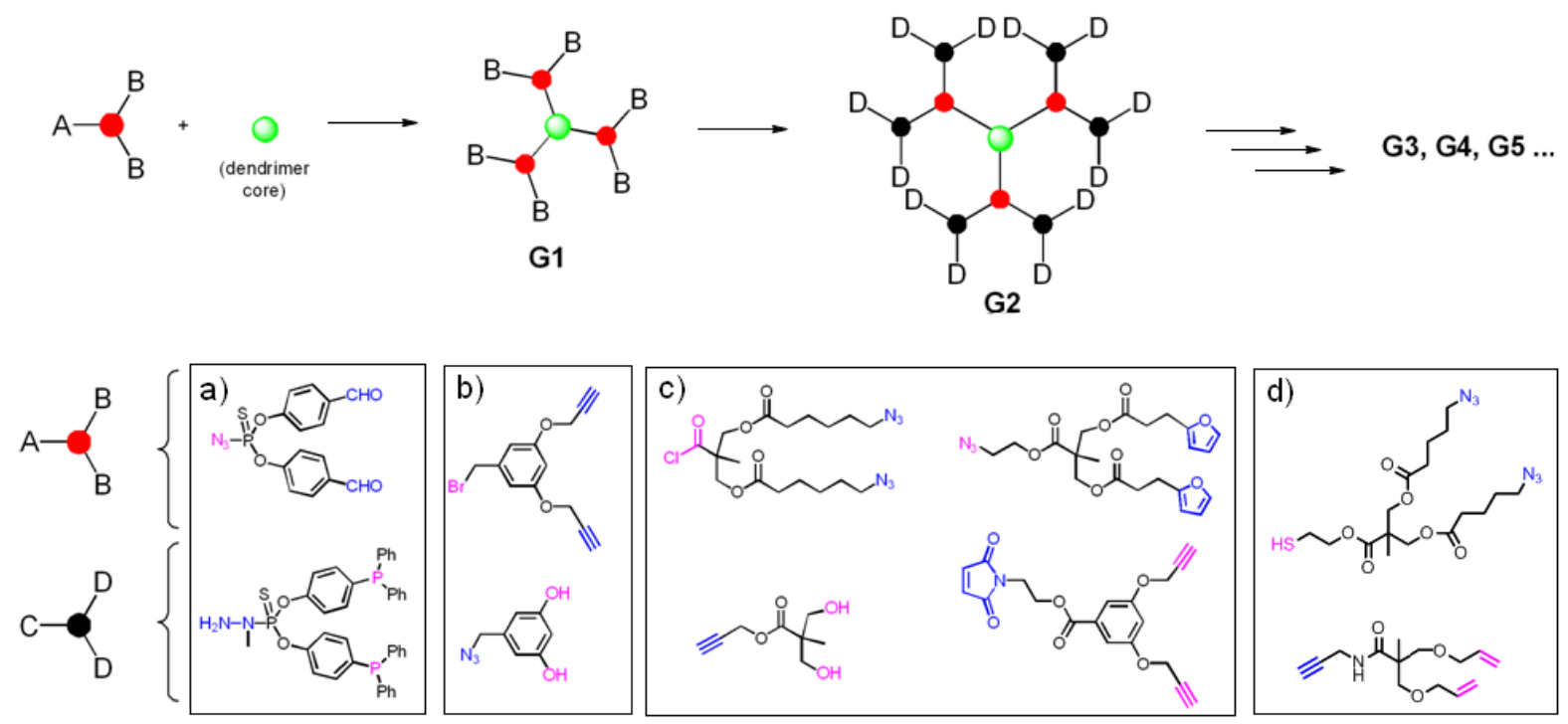

2 Figure 3

3
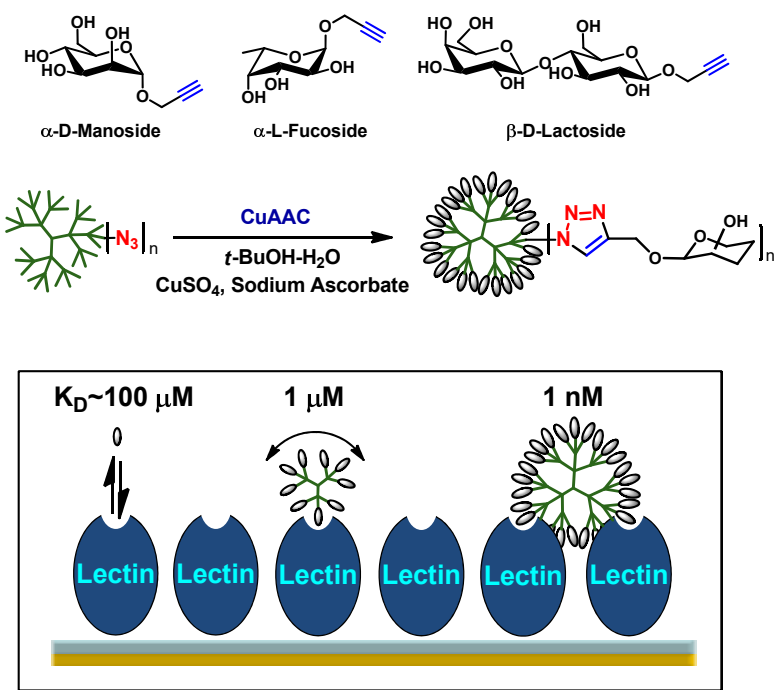

$5 \quad$ Figure 4

Clicking Polymers for Drug Delivery 
Lallana Page 51

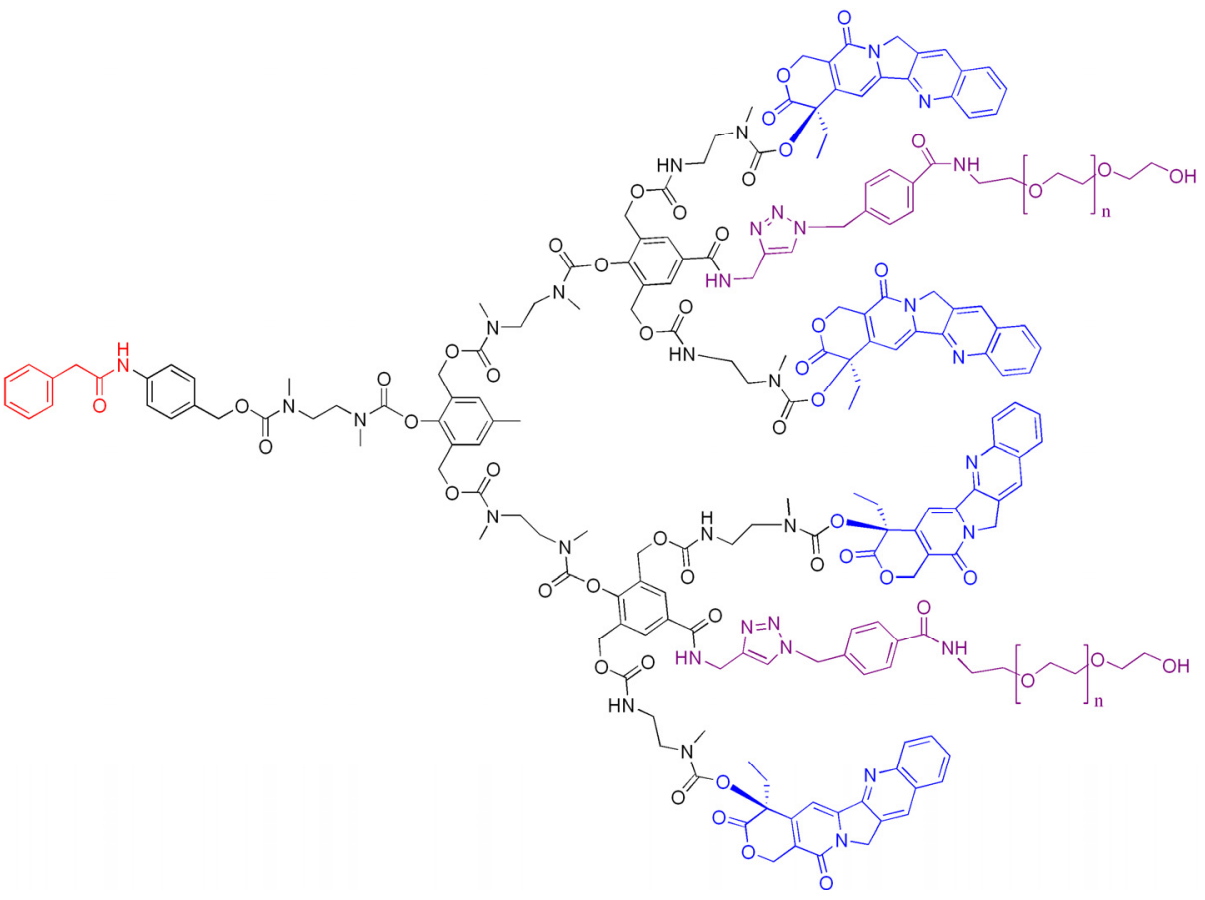

Figure 5

3
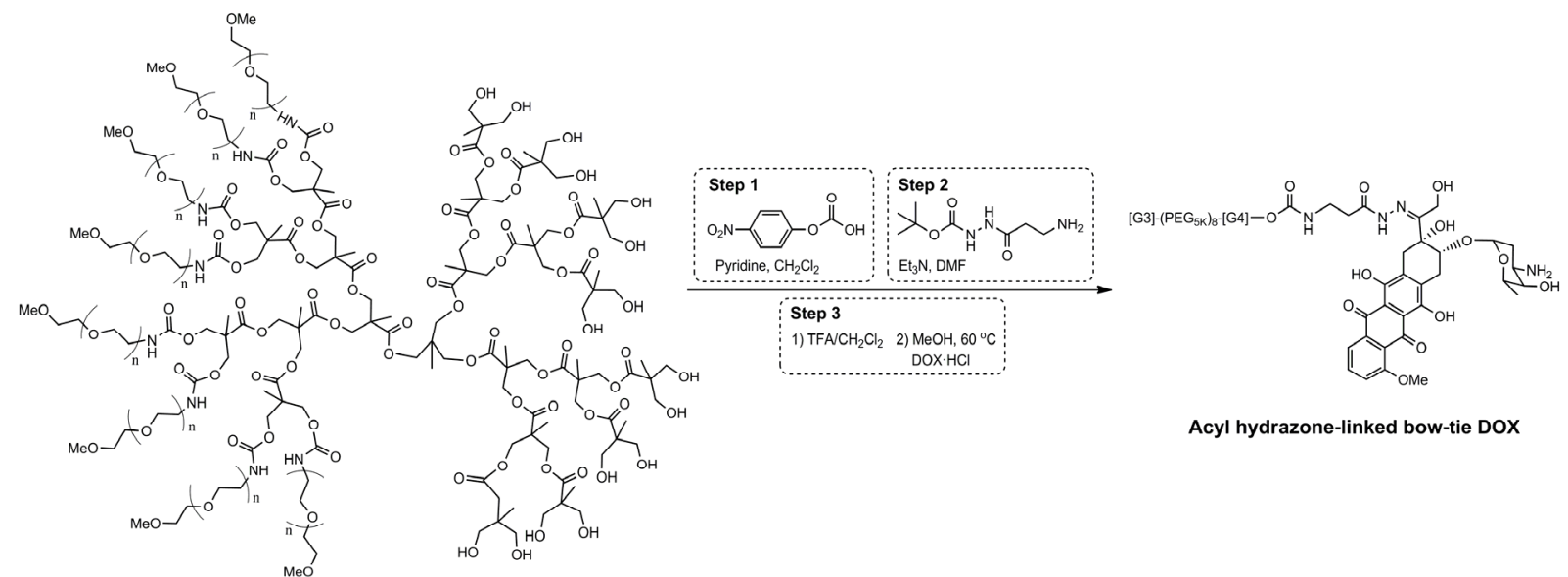

5

Figure 6 
a)
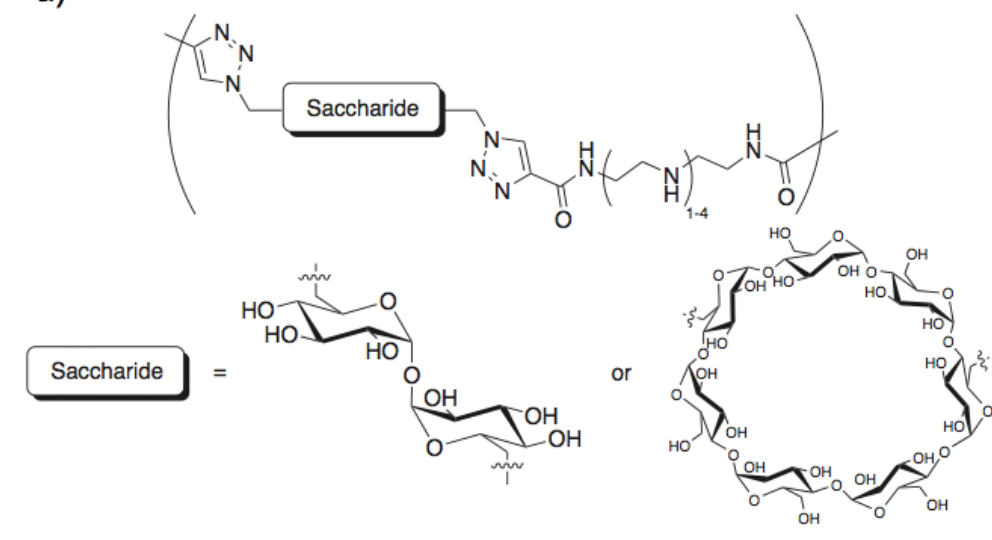

b)

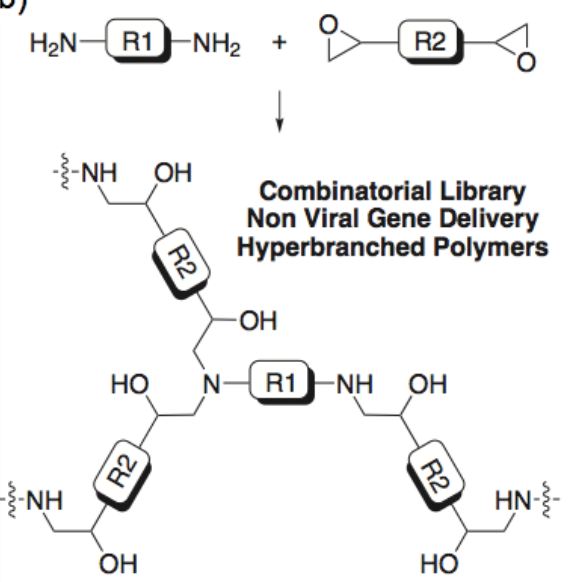

2 Figure 7

3

a)

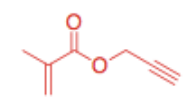

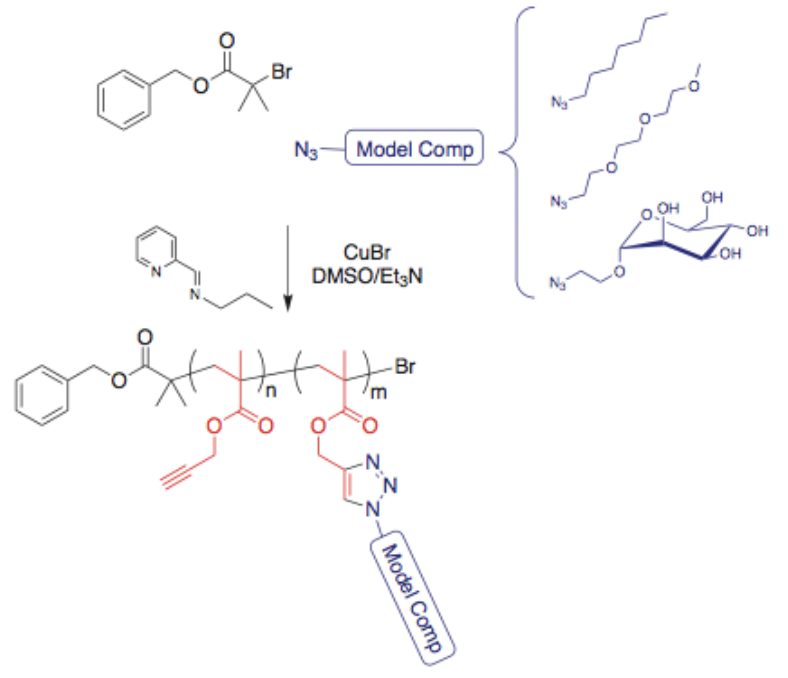
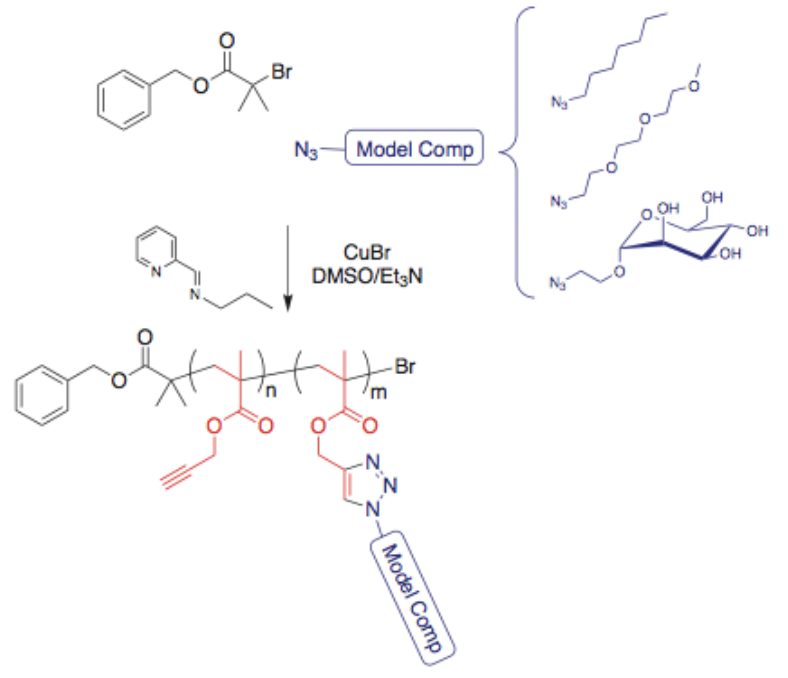

4

Figure 8

Clicking Polymers for Drug Delivery

b)<smiles>C=C(C)C(=O)OCC#CN</smiles>
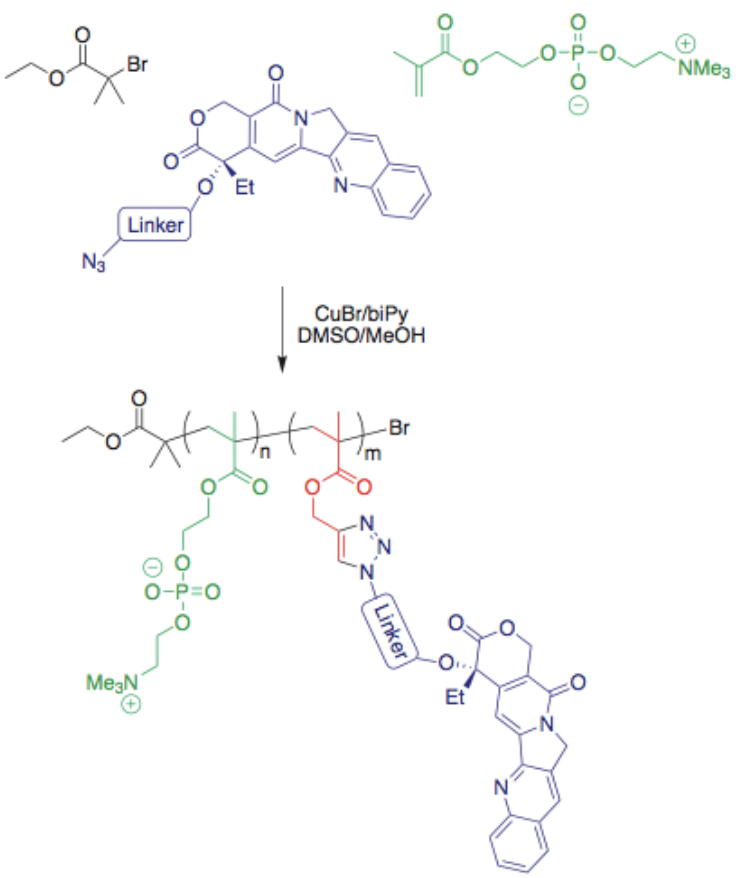
Lallana Page 53

a)

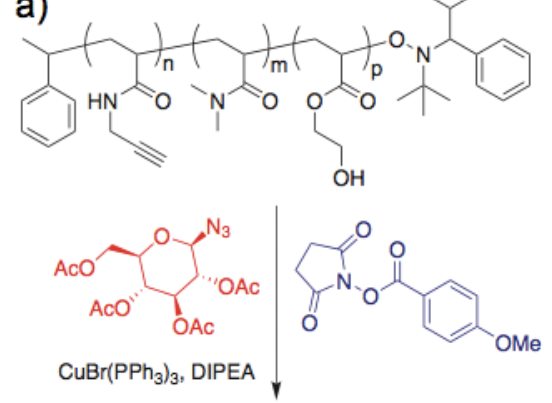

$\mathrm{C}_{0}$

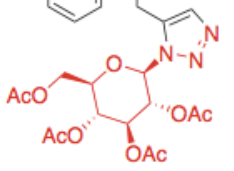

1

2

Figure 9

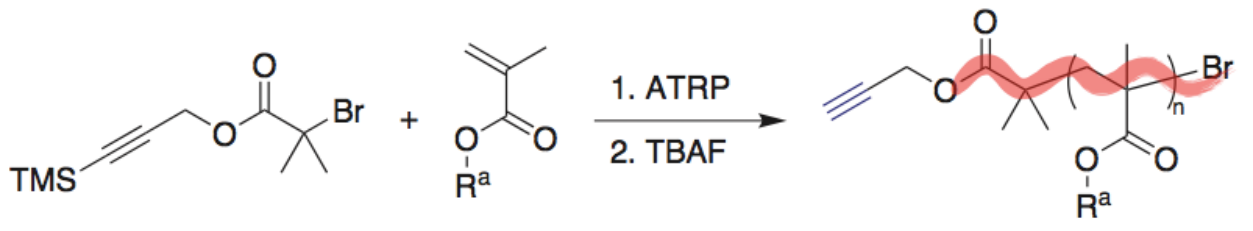

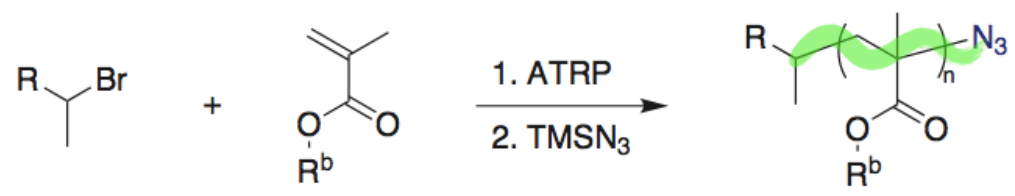

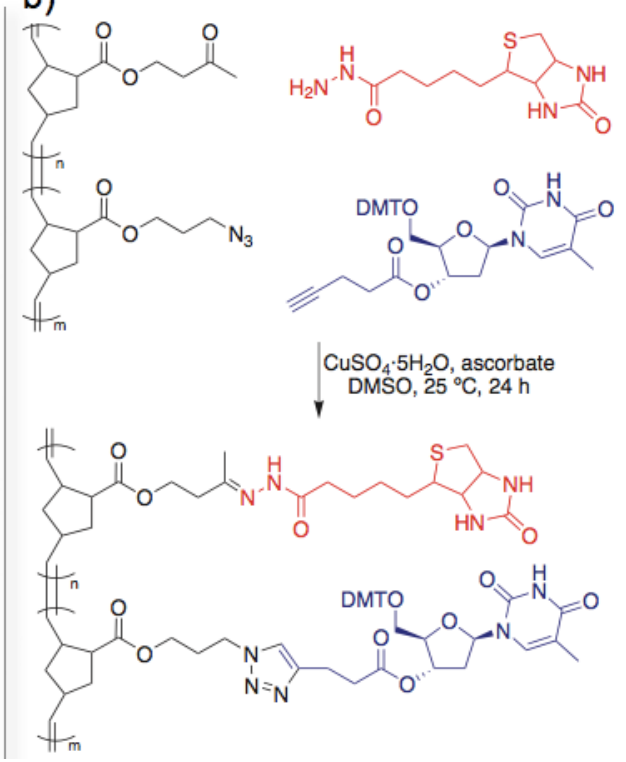<smiles>[R]C(C)CC(C)(C)C(C)(C)C(=O)OP</smiles><smiles>CCOC(=O)C=CCCCCCC(C)(Br)C(F)(F)F</smiles><smiles>O=C1CCCCC1</smiles>

$\mathrm{R}^{\mathrm{a}}$<smiles>[R]C(C)CC(C)(C)C(C)(C)C(=O)OCc1cn(C(C)(C)C(=O)OCc2cn(C(C)(C)C(=O)OP)nn2)nn1</smiles>

$4 \quad$ Figure 10 


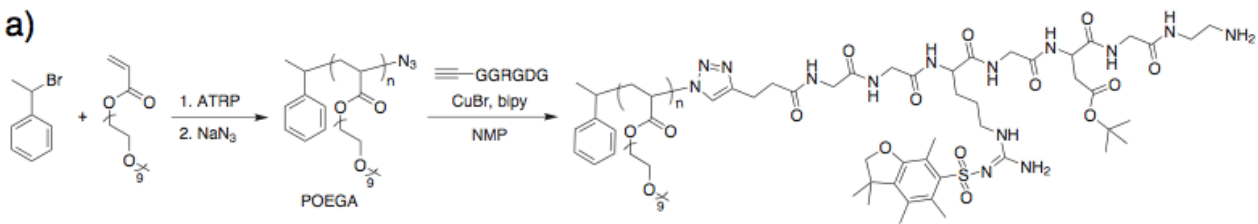

b)
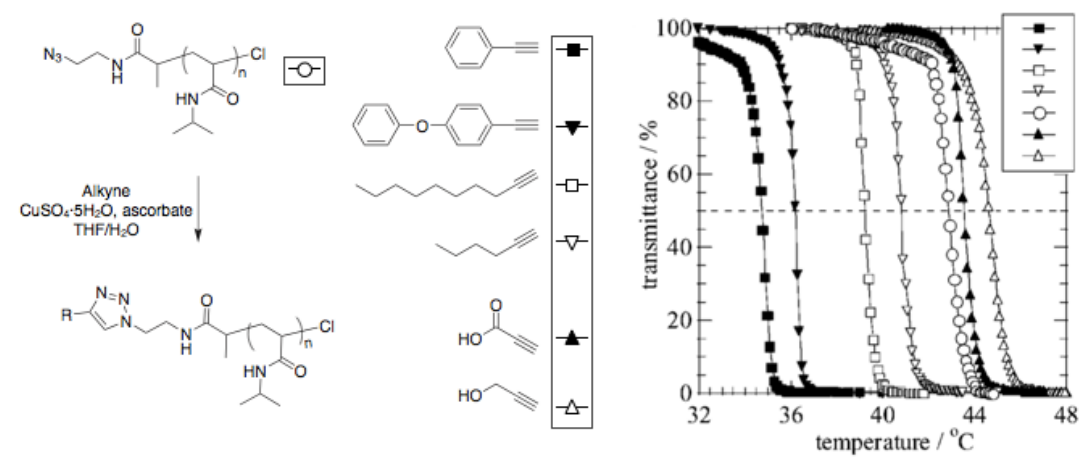

2 Figure 11

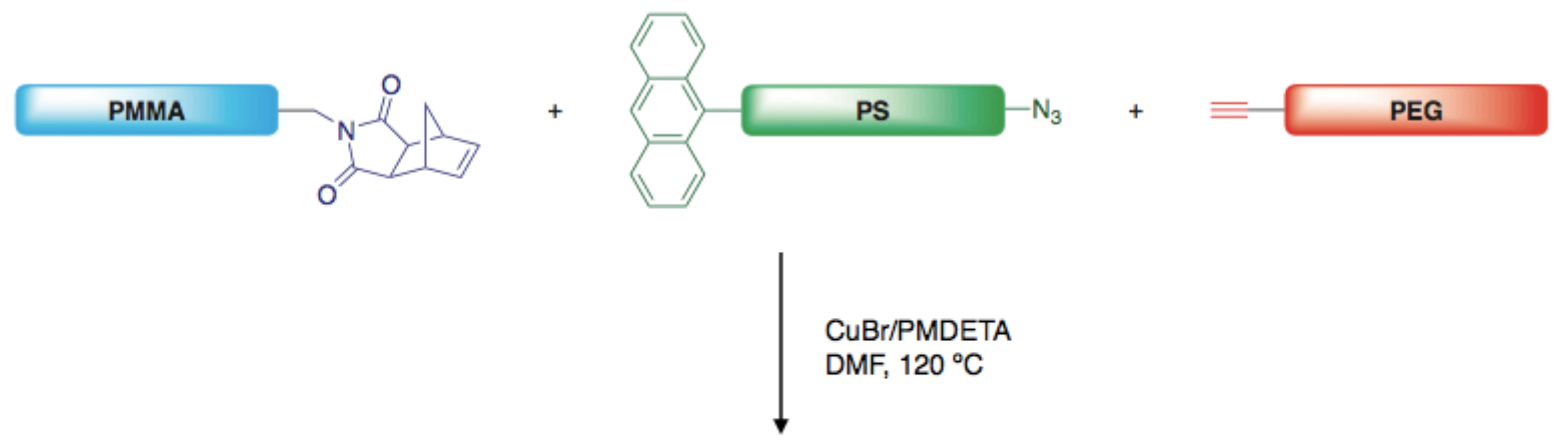

3

$4 \quad$ Figure 12 


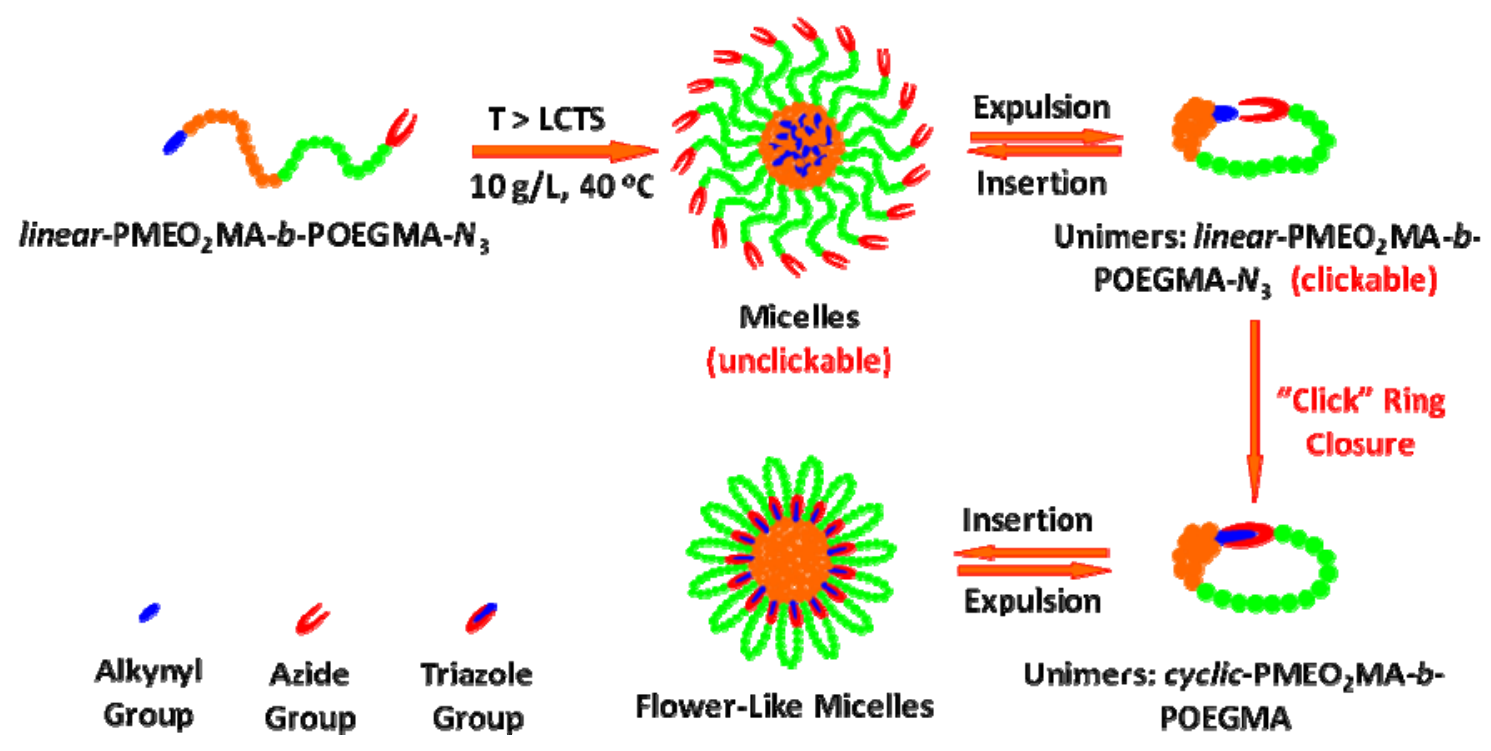

2 Figure 13

3

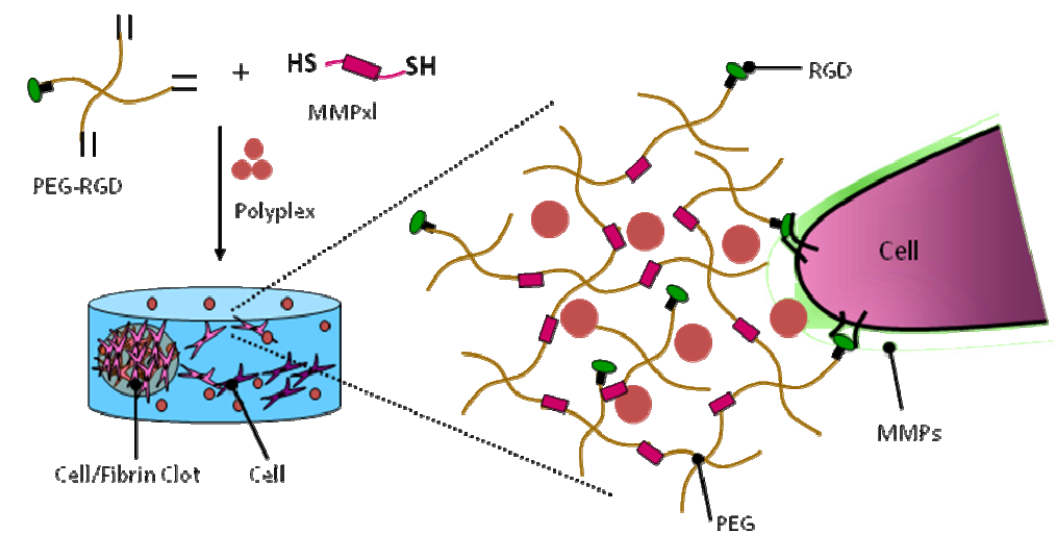

$5 \quad$ Figure 14

Clicking Polymers for Drug Delivery 


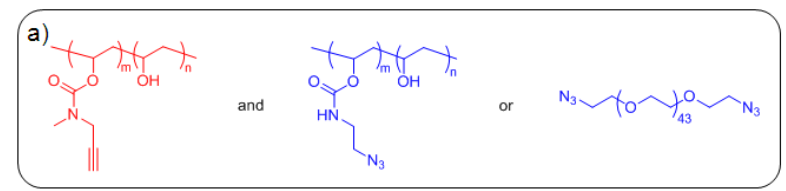

b)
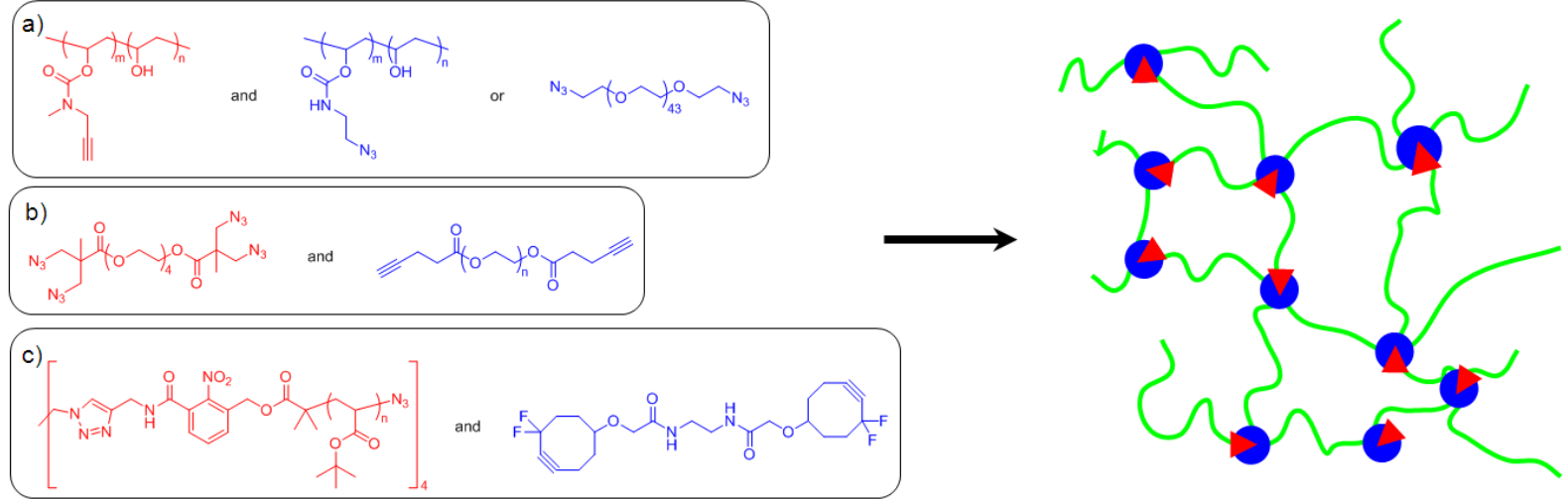

2 Figure 15 

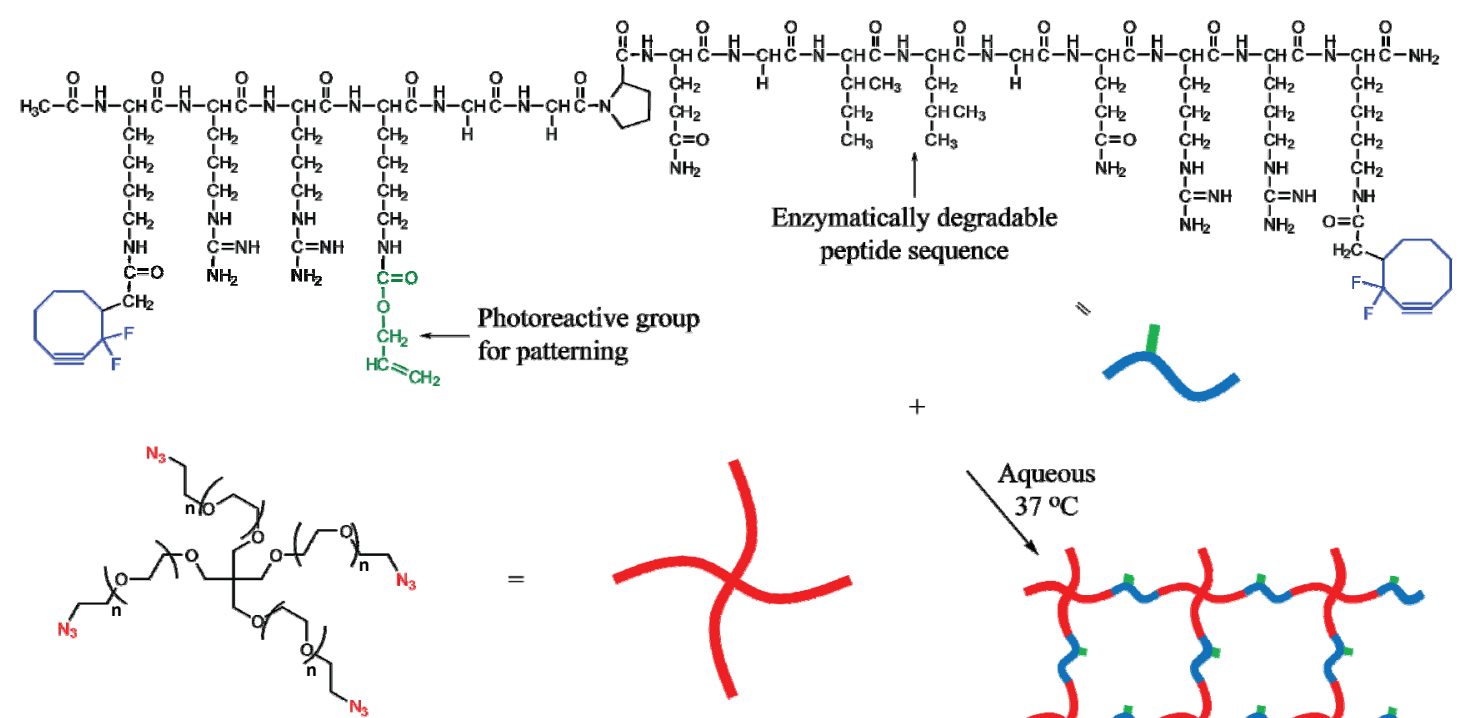

Poly(ethylene glycol) Tetraazide Mol. Wt.: $\sim 10000$
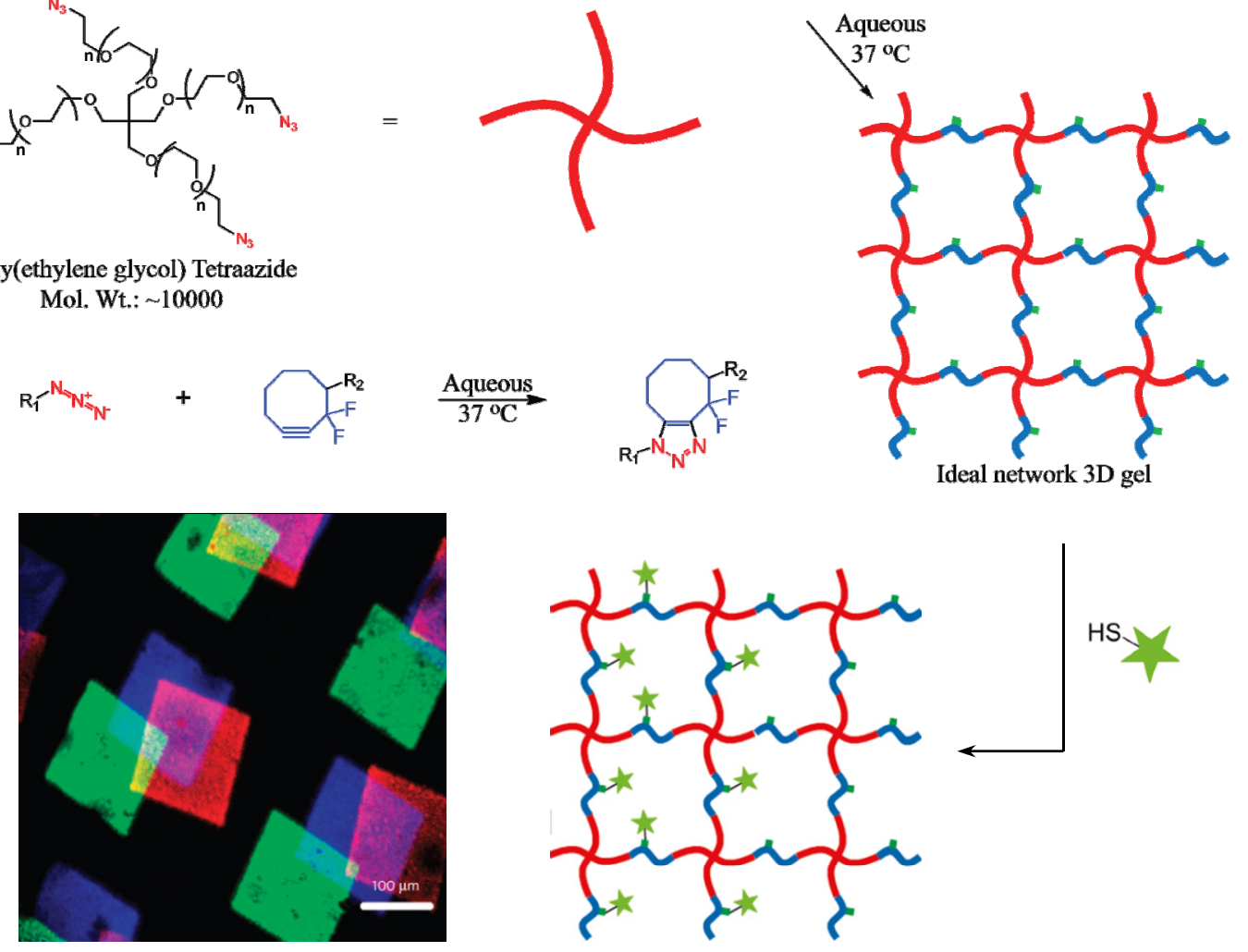

2 Figure 16 